\title{
Review of the Philippine taxa formerly assigned to the Genus Amphicnemis Selys. Part III. Genus Pericnemis: Bonita- and Incallida- groups with descriptions of four new species (Odonata: Coenagrionidae)
}

\author{
Reagan Joseph T. Villanueva ${ }^{1,2^{*}}$, Rory A. Dow ${ }^{2}$
}

\begin{abstract}
The species formerly assigned to the genus Amphicnemis Selys, 1863 in the Philippines are reviewed. The present paper is the third of a series and deals with the species transferred to the genus Pericnemis Hagen in Selys, 1863. Specimens used in the study are all deposited in museums collections. The bonita- and incallida-groups of Pericnemis from the Philippines are characterized. A key to species groups within Pericnemis is given, and also a key to the males of the bonita- and incallida-groups. The bonita-group includes five species: P. bonita Needham \& Gyger, 1939, P. flavicornis Needham \& Gyger, 1939, P. bisaya spec. nov., P. gili spec. nov. and P. muragbonita spec. nov. The incallida--group includes two species: P. incallida Needham \& Gyger, 1939 and $P$. yakal spec. nov. Descriptions and illustrations are provided of both sexes of all species.
\end{abstract}

Keywords: Zygoptera, biodiversity, taxonomy, Philippines

\section{Introduction}

Villanueva (2012) reviewed species from the Philippines that had previously been treated as members of Amphicnemis Selys, 1863 all of which were transferred to Pericnemis Hagen in Selys, 1863, or assigned to the newly established genera Luzonobasis Villanueva, 2012, Pandanobasis Villanueva, 2012, and Sangabasis Villanueva, 2012. Species belonging to Luzonobasis and Pandanobasis were dealt with in Villanueva (2012), and those in Sangabasis were treated in detail in Villanueva \& Dow (2014). In the present paper, part of the Pericnemis species are treated, tentative species groups are established based on wing venation and structure of the genital ligula and cerci. Two of these groups are here treated in detail.

The biology and ecology of Philippine Pericnemis are inadequately known. Unpublished data suggest that the three

\footnotetext{
${ }^{1}$ College of Arts and Sciences Education, University of Mindanao, Matina, Davao City, 8000 Philippines

${ }^{2}$ Naturalis Biodiversity Center, P.O. Box 9517, 2300 RA Leiden, The Netherlands

*Corresponding email: rjtvillanueva@gmail.com

Date Submitted: 21 July 2019

Date Accepted: 11 February 2020
}

groups occupy a particular niche. Field observations show that members of the Pericnemis bonita-group are encountered in forested streams with many standing pools. This is contrary to those of the Pericnemis lestoides-group that prefer forested flowing streams. Pericnemis incallida-group is as unique as its Bornean relatives which prefer tree holes as breeding habitat.

Based on the materials examined for this paper, and the new materials that came to the primary author's attention, the total number of species in these two groups treated here is expected to double in number.

\section{Materials and Methods}

This paper is based primarily on the specimens from the R.A. Müller collection now preserved in Naturalis Biodiversity Center (RMNH), formerly National Museum of Natural History, in Leiden, The Netherlands. The Philippine Amphicnemis specimens from Senckenberg Museum Frankfurt (SMF), collected by G. Boettcher in 1913-1918, and the Amphicnemis specimens from the V.P. Gapud collection in the University of the Philippines-Los Baños (UPLB), and the first author's personal collection from students requesting identifications now deposited in the University of Mindanao, Davao City, Philippines, were also studied. Name bearing types of species described by Needham \& Gyger (1939) were not examined. 
Instead we have relied on the published descriptions and on the specimens at RMNH and SMF, identified by M.A. Lieftinck and M. Hämäläinen. Terminology generally follows Watson \& O'Farrell (1991).

Acronyms for collections are as follows:

RMNH: Naturalis Biodiversity Center, Leiden, NETHERLANDS

RJTV: Coleoptera Research Center, University of Mindanao, Davao City, PHILIPPINES

SMF: Senckenberg Museum, Frankfurt, GERMANY

UPLB: V.P. Gapud Collection, University of the Philippines, Los Baños Campus, Laguna, PHILIPPINES

\section{Systematic}

\section{Pericnemis Hagen in Selys, 1863}

Villanueva (2012) characterizes Pericnemis by the presence of a distinct tubercle or ridge on the shaft of the genital ligula (shared with Sangabasis), a short epiproct, weakly concave postocular areas on the head without a tubercle there or on the dorsal carina, cerci with a simple upper branch and long lower branch and the origin of R4 close to the subnodus. Within Pericnemis four subgroups can be recognized: the $P$. sticticagroup, $P$. bonita-group, $P$. lestoides-group and $P$. incallidagroup.

Pericnemis stictica-group: The group accommodates the species from Sundaland: $P$. dowi Orr \& Hämäläinen, 2013, $P$. kiautarum Orr \& Hämäläinen, 2013, P. stictica Hagen in Selys, 1863 and $P$. triangularis Laidlaw, 1931. This group is characterized by a large, rounded tubercle on the distal part of the shaft of the genital ligula. The terminal segment of the genital ligula is relatively elongate without subapical arms. The pterostigma is rather variable in form. Three of these species are endemic to Borneo, but $P$. stictica is known from Borneo, Java, Peninsular Malaysia, Sumatra and Thailand. Orr \& Hämäläinen (2013) discussed the named species of this group. Additionally there may be an unnamed species only known from a female from Terengganu in eastern Peninsular Malaysia (Choong et al. 2012). This group is of no further concern in this publication.

Pericnemis bonita-group: The group accommodates two of the earlier known Philippine species, and an additional three new species described here. It resembles the stictica-group in having a large, broad, rounded tubercle on the shaft of the genital ligula, but the terminal segment is shorter and possesses subapical arms. The pterostigma is four-sided and distally followed by a single row of cells. This group is confined to the Philippines and includes $P$. bisaya spec. nov., $P$. bonita, $P$. flavicornis, $P$. gili spec. nov., and $P$. muragbonita spec. nov.

Pericnemis incallida-group: This is the most poorly known group with very few specimens available. Specimens have a short, ridge-like or flat, tubercle on the shaft of the genital ligula, similar to that in the $P$. lestoides-group. The pterostigma has a short costal side, half the length of subcostal side. The cerci are sub-cylindrical with a flattened middle third. The anterior part of the frons is broader than the postclypeus. The group is confined to the Philippines and its members are by far the largest damselflies among the Philippine coenagrionids. Species included are $P$. incallida and $P$. yakal spec. nov.

Pericnemis lestoides-group: This is by far the most speciose group. Two named species and a number of new, as-yet -unnamed, species are placed in it. The group is characterized by the narrow tubercle on the distal part of the shaft of the genital ligula. The terminal segment of the genital ligula is bilobed. The costal side of pterostigma is at least $2 / 3$ the length of the subcostal side. The upper branch of the cerci is cylindrical or sub-cylindrical. The group is confined to the Philippines and the only named species in it are P. lestoides (Brauer, 1868) and $P$. melansoni Villanueva, Medina \& Jumawan, 2013; this group will be dealt with in detail in the last part of this series (Villanueva, in preparation).

\section{Key to the subgroups}

A key to the groups occurring in the Philippines is presented and separate keys (male only) are provided for the $P$. bonita- and $P$. incallida-groups.

1 Distal portion of the shaft of the genital ligula with robust rounded tubercle overlapping the apex of the terminal segment in normal resting position (Fig. 1a)

P. bonita-group

Distal portion of the shaft of the genital ligula with ridge or smaller tubercle not overlapping (Figs 1b, 1c) ............... 2 .

2 Pterostigma with costal side half the length of subcostal side $P$. incallida-group.

- Pterostigma with costal side at least $2 / 3$ the length of subcostal side $P$. lestoides-group.

\section{Pericnemis bonita-group Key to males}

1 Lateral extremities of the posterior pronotal lobe strongly produced to posteriad as long sharply pointed spurs (Figs 8a, 8c) 
- Lateral extremities of the posterior pronotal lobe only slightly

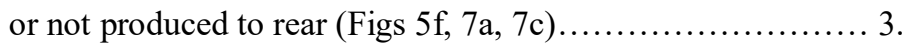

2 Lower margin of lateral extremity of posterior pronotal lobe strongly convex before spur (Fig. 8a); upper branch of cercus tapering in lateral view; whole cercus running approximately straight and slightly turned down after base (Fig. 17b) .......... P. flavicornis Needham \& Gyger, 1939 - Lower margin of lateral extremity of posterior pronotal lobe straight or only slightly convex before spur (Fig. 8c); upper branch of cercus expanded in distal ca one-third, whole cercus curved over entire length (Fig. 17d).

$P$. gili spec. nov.

3. Lower lateral margin of the posterior pronotal lobe sinuous (Fig. 7a) .................................. P. bisaya spec. nov. - Lower lateral margin of posterior pronotal lobe not sinuous (Figs 5f, 7c) 4.

4 Mesepisternal black stripe narrow for most of its length, only broadened in the anterior one quarter (Fig. 11c); lateral extremity of posterior pronotal lobe deeply angulate (Fig. 7c)

\section{P. bonita Needham \& Gyger, 1939.}

- Mesepisternal black stripe broad, nearly parallel-sided (Fig. 11e); lateral extremity of posterior pronotal lobe rounded (Fig. 5 f) $P$. muragbonita spec. nov.

\section{Pericnemis bonita Needham \& Gyger, 1939}

(Figs 1a, 2c, 2d, 5c, 5d, 7c, 7d, 10b, 11c, 11d, 12c, 12d, 15b, $16 \mathrm{c}, 16 \mathrm{~d})$

Pericnemis bonita Needham \& Gyger 1939: 292-293, Figs. 260, 261, 306 (original description both sexes, Mt. Makiling, Luzon).

Amphicnemis bonita (Needham \& Gyger 1939); — Lieftinck 1957: 163-164 (in part, Luzon); — Hämäläinen \& Müller 1997: 259, 278 (Luzon and Marinduque; note 35); - Gapud 2006: 35; — Ramos \& Gapud 2007: 55, Fig. 40.

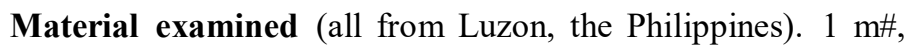
Los Baños, Laguna, 50m, 6 iv 1949, leg. L.B. Uichanco, in RMNH; 1 m\#, 1 f\#, Los Baños, Laguna, 13 xii 1953, leg. H.

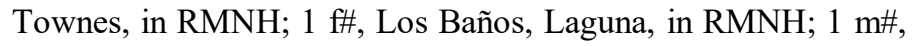
Los Baños, Laguna, 20 ii 1914, G. Boettcher, in SMF; 1 f\#,

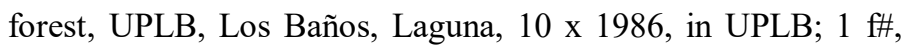
"mudspring area, forested area", Mt. Makiling, Laguna, 30.xi.1987, leg. V.P. Gapud, in UPLB; 1 m\#, Flat Rocks, Mt. Makiling, Laguna, 16 ii 2000, leg. A.A. Candelaria, in UPLB; 1 m\#, Mudspring area, Mt. Makiling, Laguna, 5 v 1988, in UPLB;
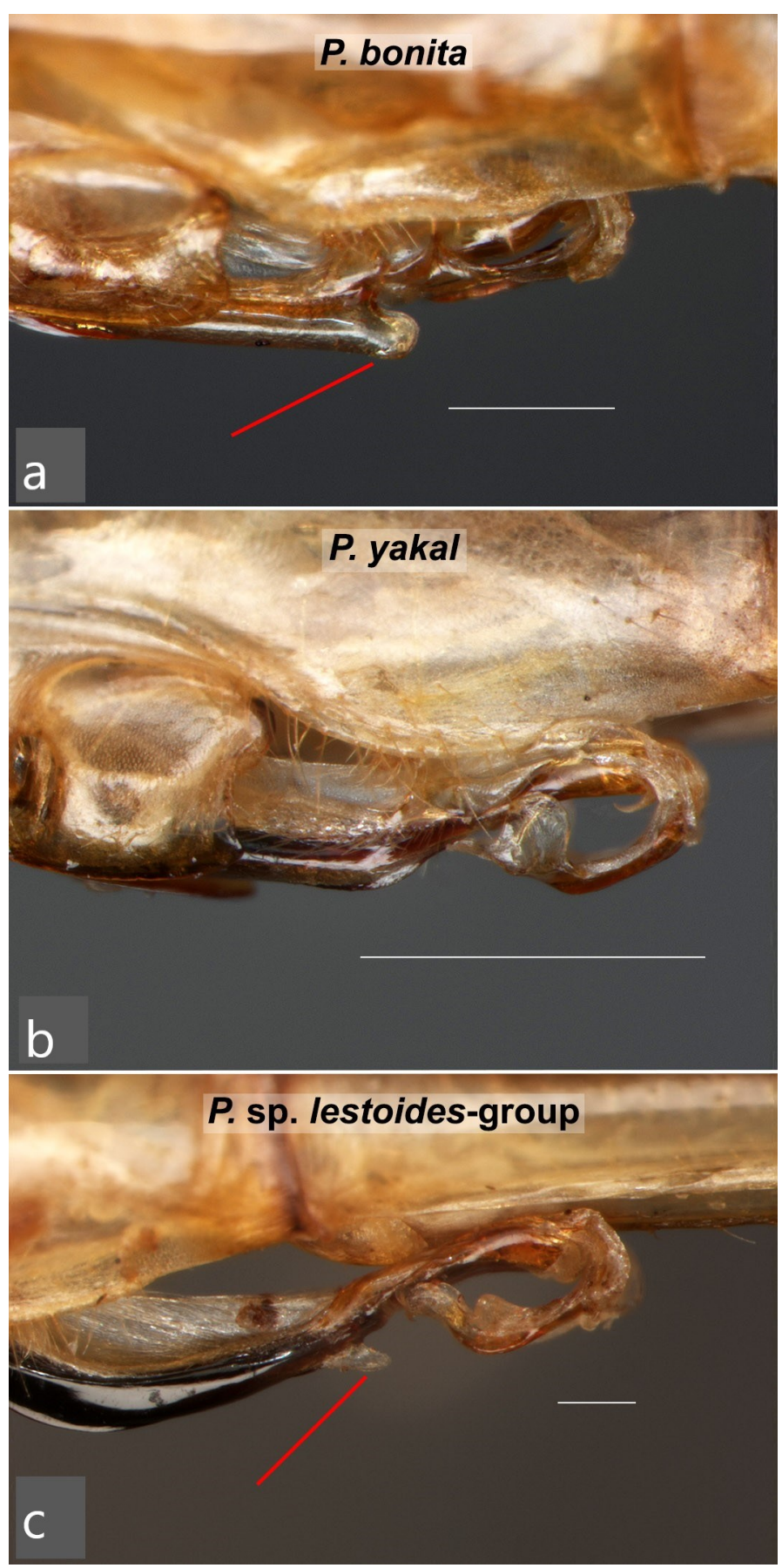

Figures 1a-c. Lateral view of genital ligula for species groups of Philippine Pericnemis. (1a) P. bonita-group: $P$. bonita Los Baños, scale bar $0.2 \mathrm{~mm}$; (1b) $P$. incallida-group: P. yakal holotype, scale bar $0.5 \mathrm{~mm}$; (1c) P. lestoides-group: $P$. new species, Cateel, Davao Oriental, Mindanao, scale bae $0.2 \mathrm{~mm}$. Red lines indicate the position of the tubercle on the shaft of the genital ligula, where present (Figs 1a, 1c). 


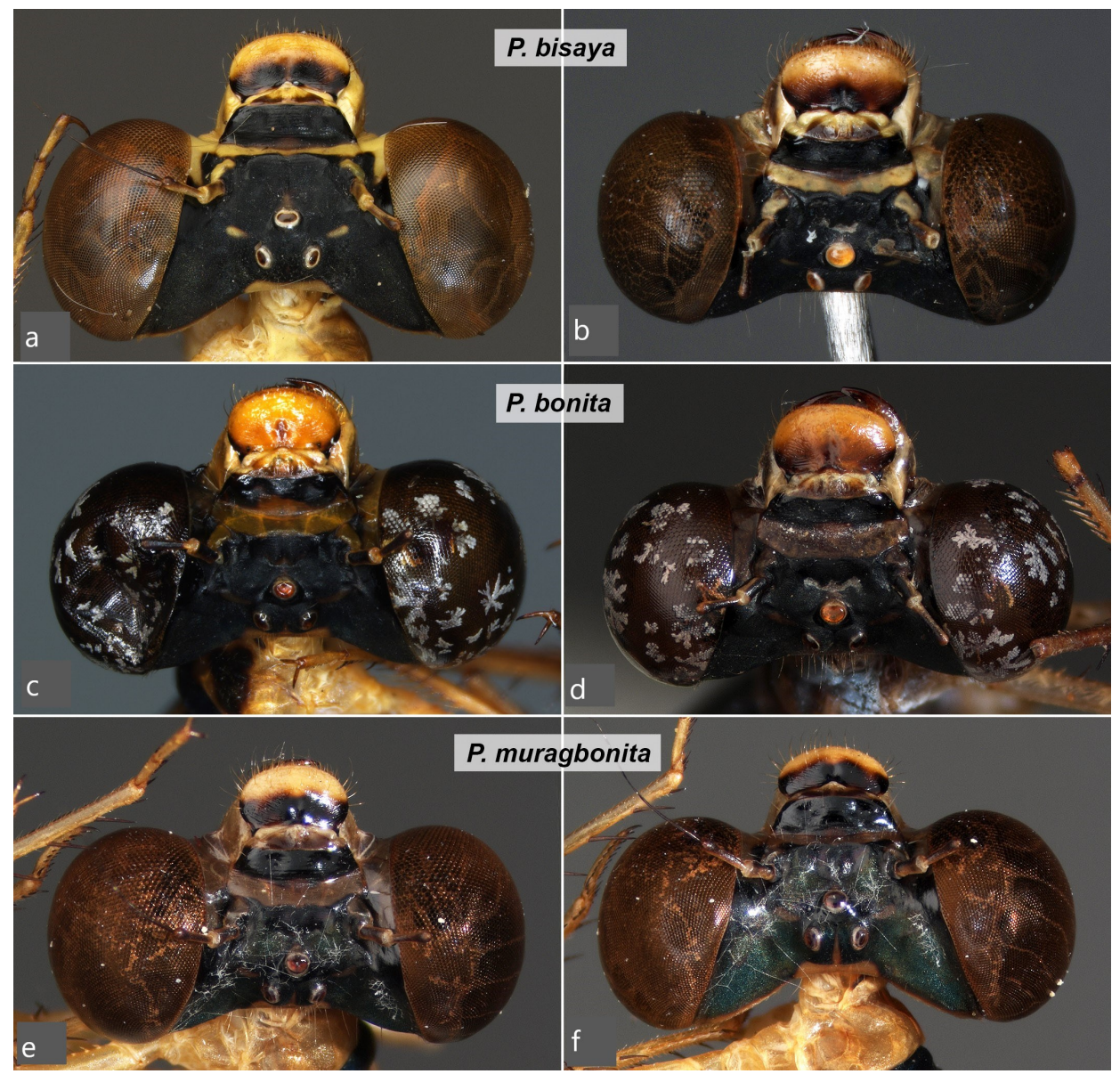

Figures 2a-f. Head of bonita-group species: (2a) P. bisaya holotype, dorsal view; (2b) P. bisaya female paratype dorso-frontal view; (2c) $P$. bonita male, Los Baños, dorso-frontal view; (2d) $P$. bonita female, Los Baños, dorso-frontal view; (2e) P. muragbonita holotype, dorso-frontal view; (2f) P. muragbonita holotype, dorsal view.

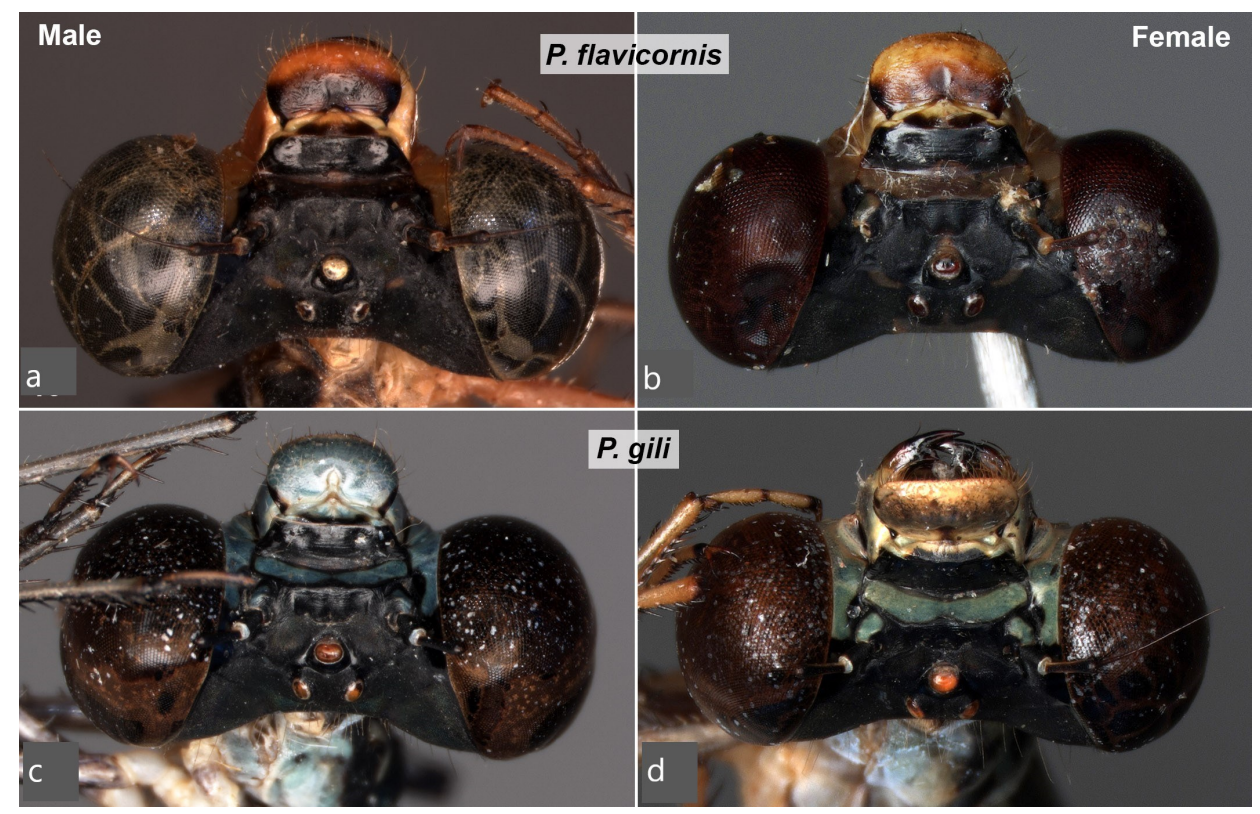

Figures 3a-d. Head of bonita-group species dorso-frontal view: (3a) P. flavicornis male, Luzon; (3b) P. flavicornis female, Luzon; (3c) P. gili holotype; (3d) $P$. gili female paratype. 


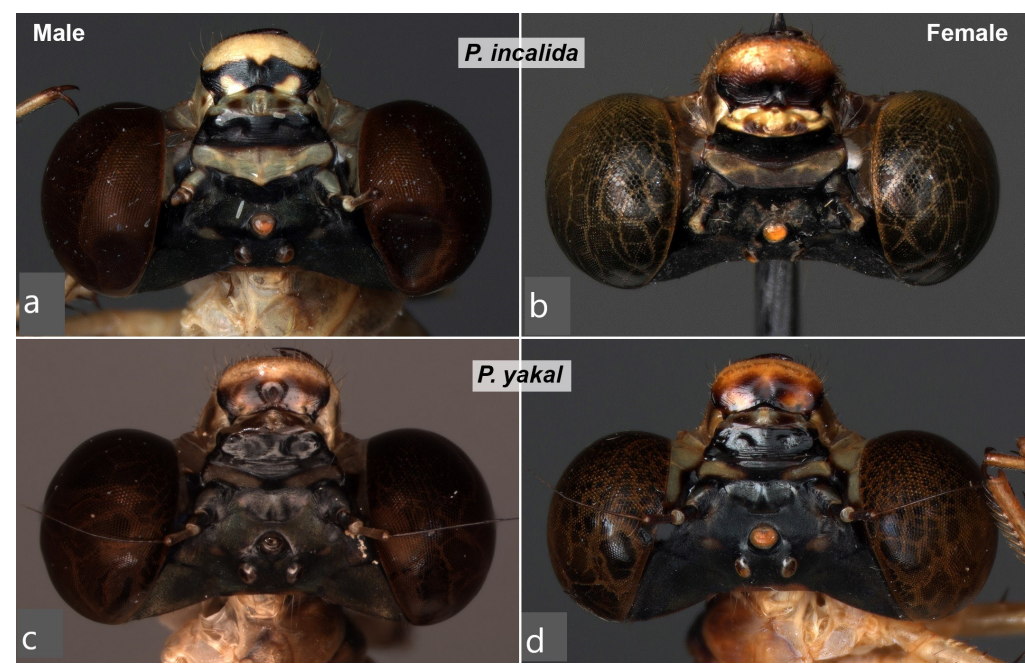

Figures 4a-d. Head of incallida-group species, dorso-frontal view: (4a) $P$. incallida male Luzon; (4b) P. incallida female; (4c) P. yakal holotype; (4d) P. yakal paratype female, Leyte.

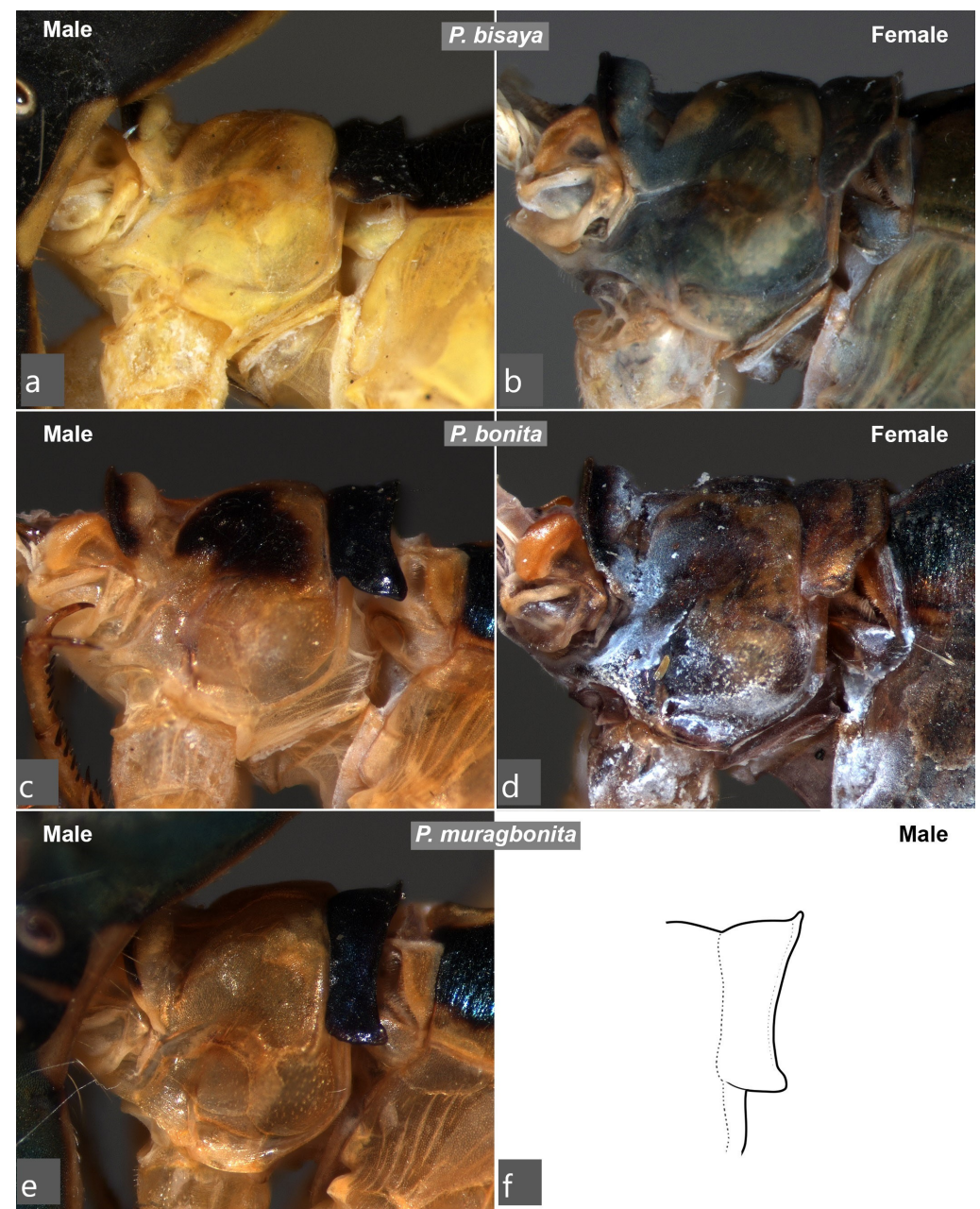

Figures 5a-f. Prothorax of bonita-group species, lateral view: (5a) P. bisaya holotype; (5b) $P$. bisaya female paratype; (5c) $P$. bonita male, Los Baños; (5d) $P$. bonita female, Los Baños; (5e) $P$. muragbonita holotype. (5f) $P$. muragbonita holotype, posterior pronotal lobe, lateral view. 


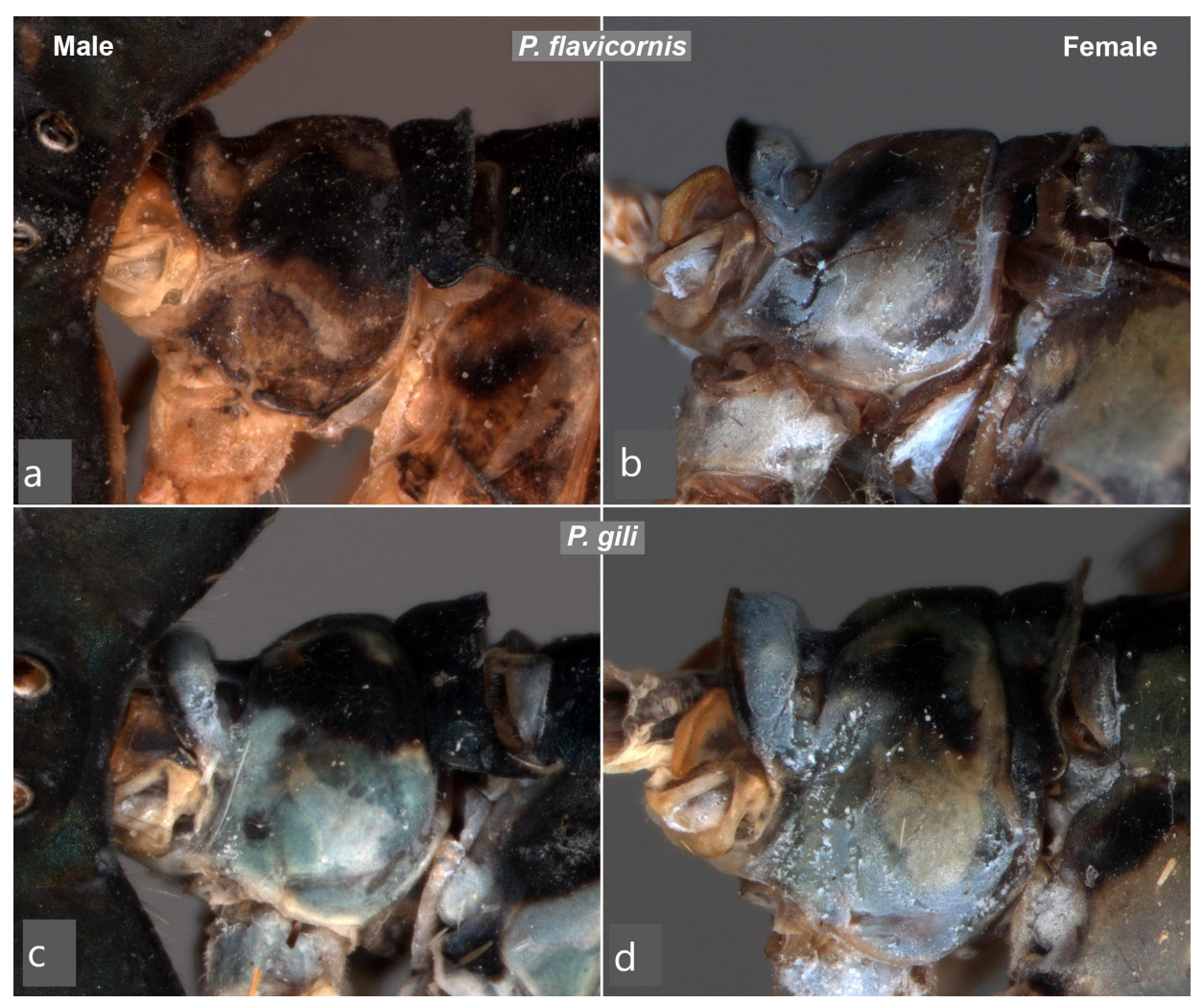

Figures 6a-d. Prothorax of bonita-group species, lateral view: (6a) P. flavicornis male, Luzon; (6b) P. flavicornis female, Luzon; (6c) P. gili holotype; (6d) P. gili female paratype.

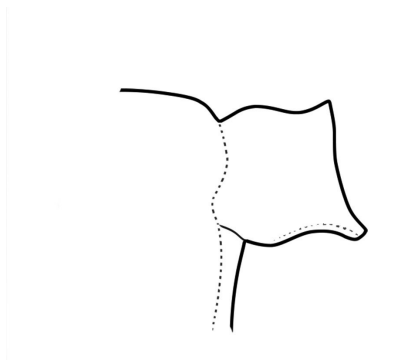

a

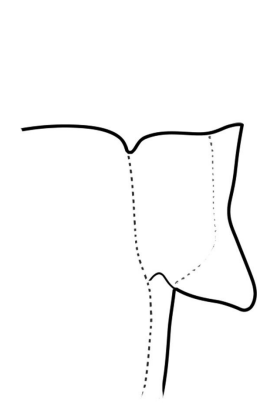

P. bisaya
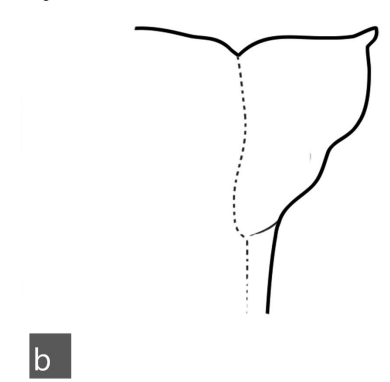

P. bonita

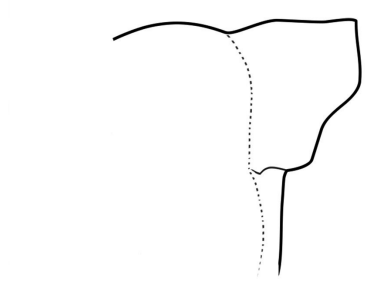

c

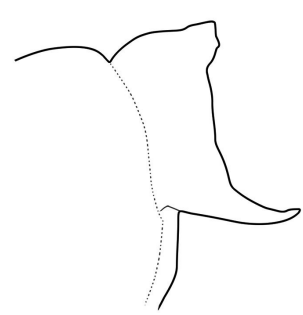

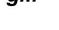
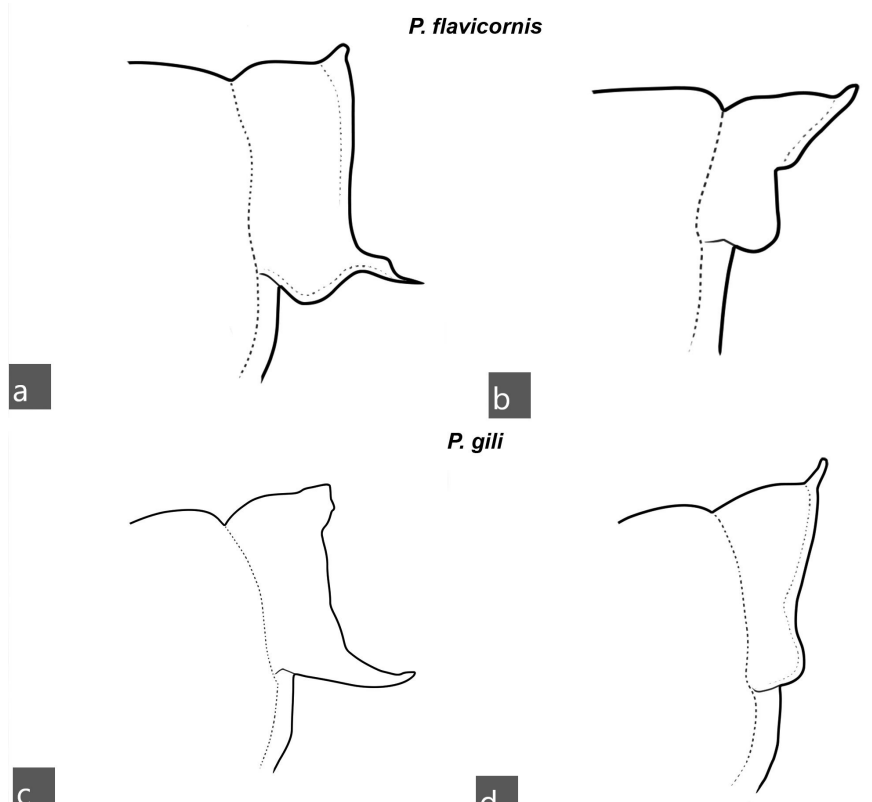

Figures 7a-d. Posterior pronotal lobe of bonita-group species, lateral view: (7a) P. bisaya holotype; (7b) $P$. bisaya female paratype; (7c) $P$. bonita male, Los Baños; (7d) P. bonita female, Los Baños.
Figures 8a-d. Posterior pronotal lobe of bonita-group species, lateral view: (8a) P. flavicornis male, Luzon; (8b) P. flavicornis female, Luzon; (8c) P. gili holotype; (8d) P. gili female paratype. 


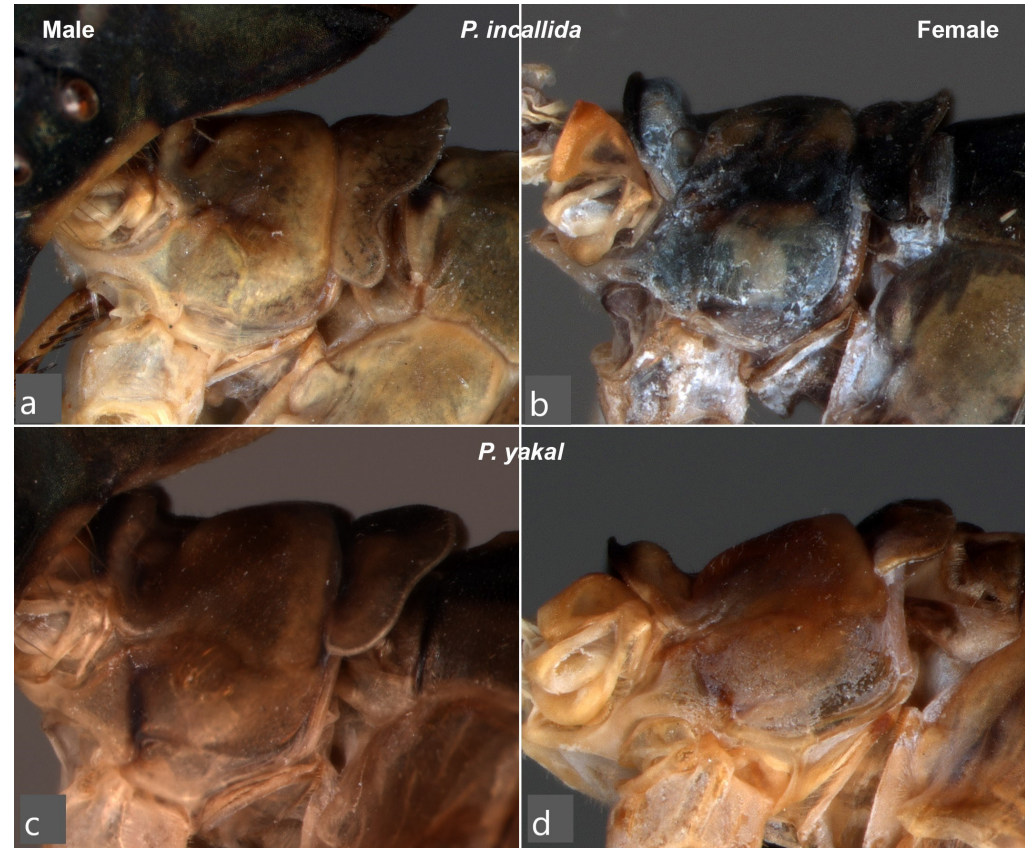

Figures 9a-d. Prothorax of incallida-group species, lateral view: (9a) $P$. incallida male Luzon; (9b) P. incallida female; (9c) P. yakal holotype; (9d) P. yakal paratype female, Leyte.

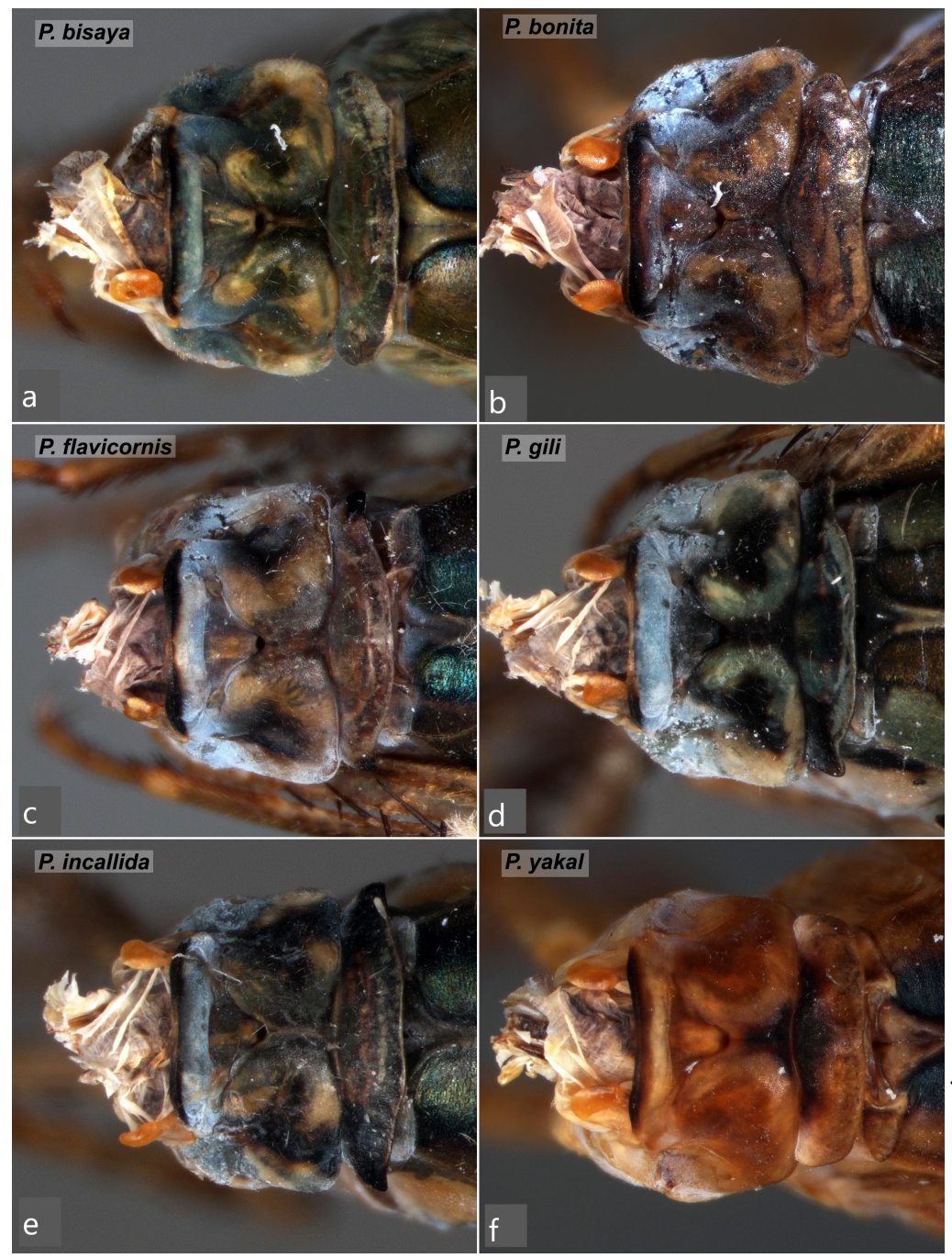

Figures 10a-f. Prothorax of bonita-group and incallidagroup species females, dorsal view: (10a) P. bisaya female paratype; (10b) P. bonita female, Los Baños; (10c) $P$. flavicornis female, Luzon; (10d) P. gili female paratype; (10e) P. incallida female; (10f) $P$. yakal paratype female, Leyte. 


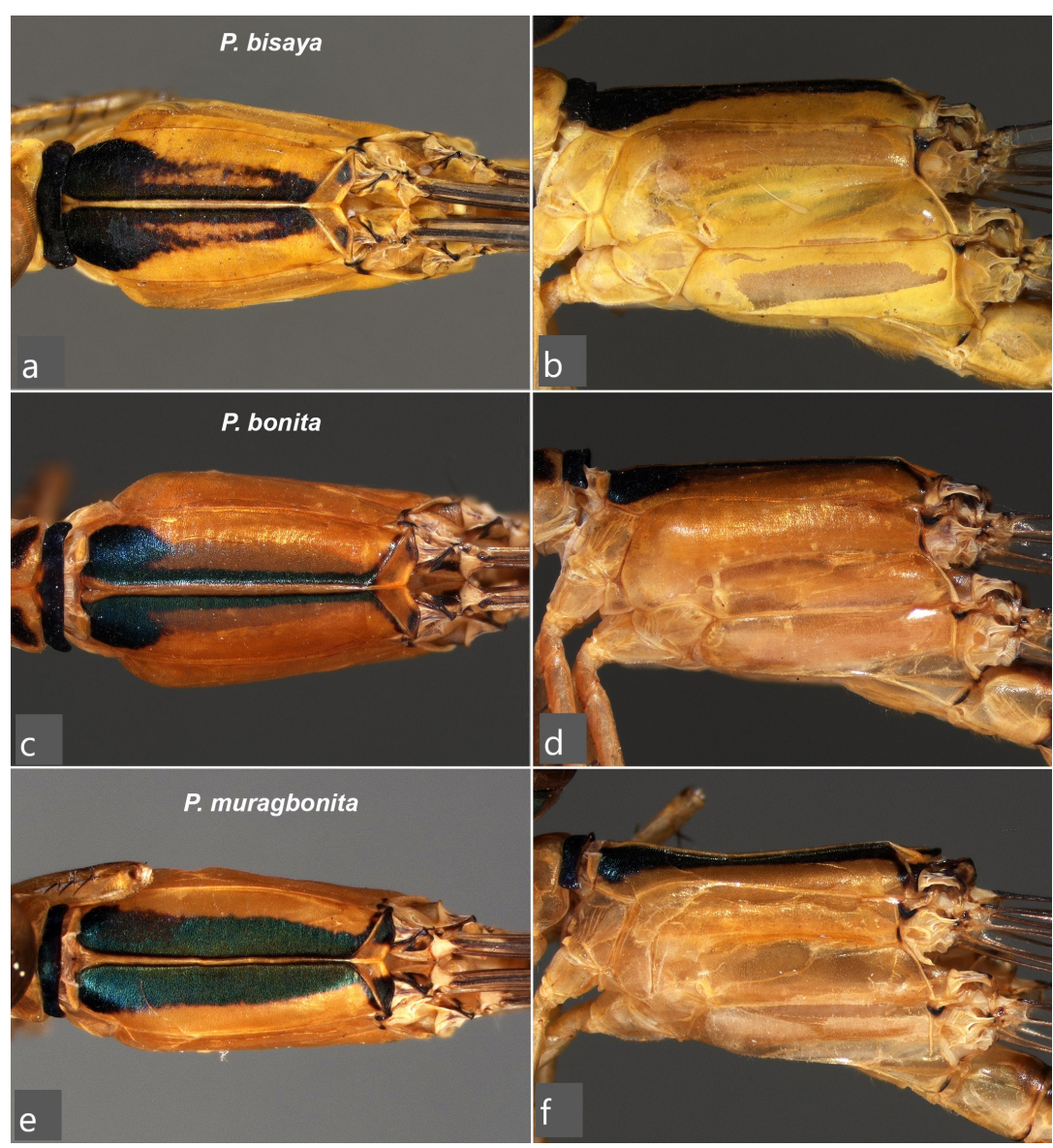

Figures 11a-f. Synthorax of males of bonita-group species: (11a) P. bisaya holotype, dorsal view; (11b) P. bisaya holotype, lateral view; (11c) P. bonita Los Baños, dorsal view; (11d) $P$. bonita Los Baños, lateral view; (11e) P. muragbonita holotype, dorsal view; (11f) P. muragbonita holotype, lateral view.

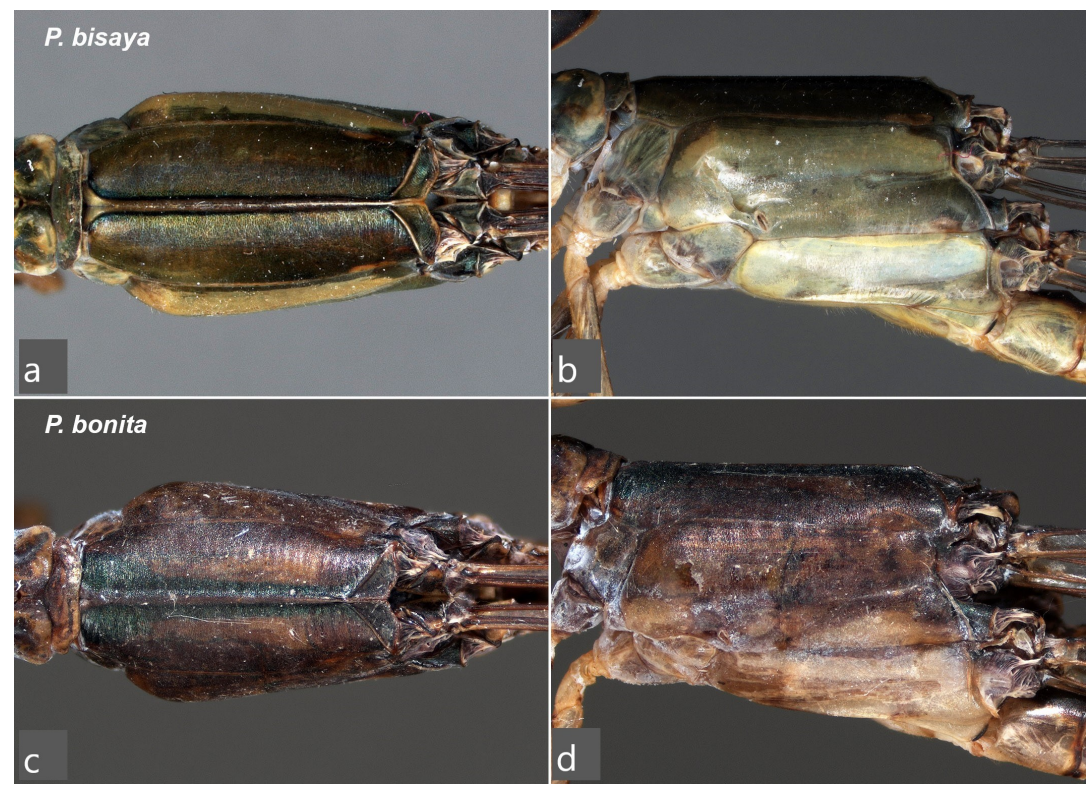

Figures 12a-d. Synthorax of females bonita-group species: (12a) P. bisaya paratype, Cebu, dorsal view; (12b) P. bisaya paratype, Cebu, lateral view; (12c) $P$. bonita, Los Baños, dorsal view; (12d) P. bonita, Los Baños, lateral view. 


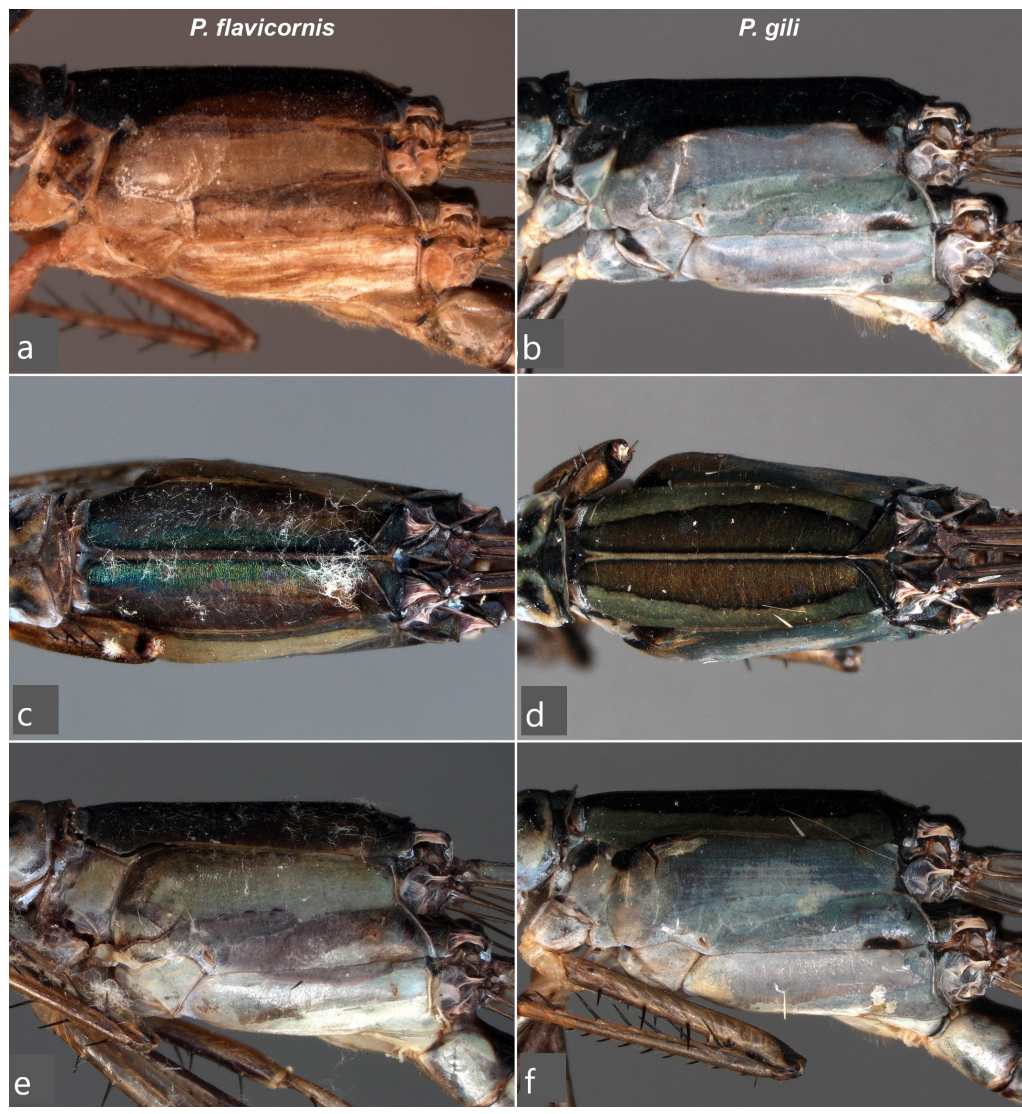

Figures 13a-f. Synthorax of bonita-group species: (13a) $P$. flavicornis male, Luzon, lateral; (13b) P. gili holotype, lateral; (13c) P. flavicornis female, Luzon, dorsal; (13d) $P$. gili female paratype, dorsal; (13e) P. flavicornis female, Luzon, dorsal; (13f) P. gili female paratype, dorsal.

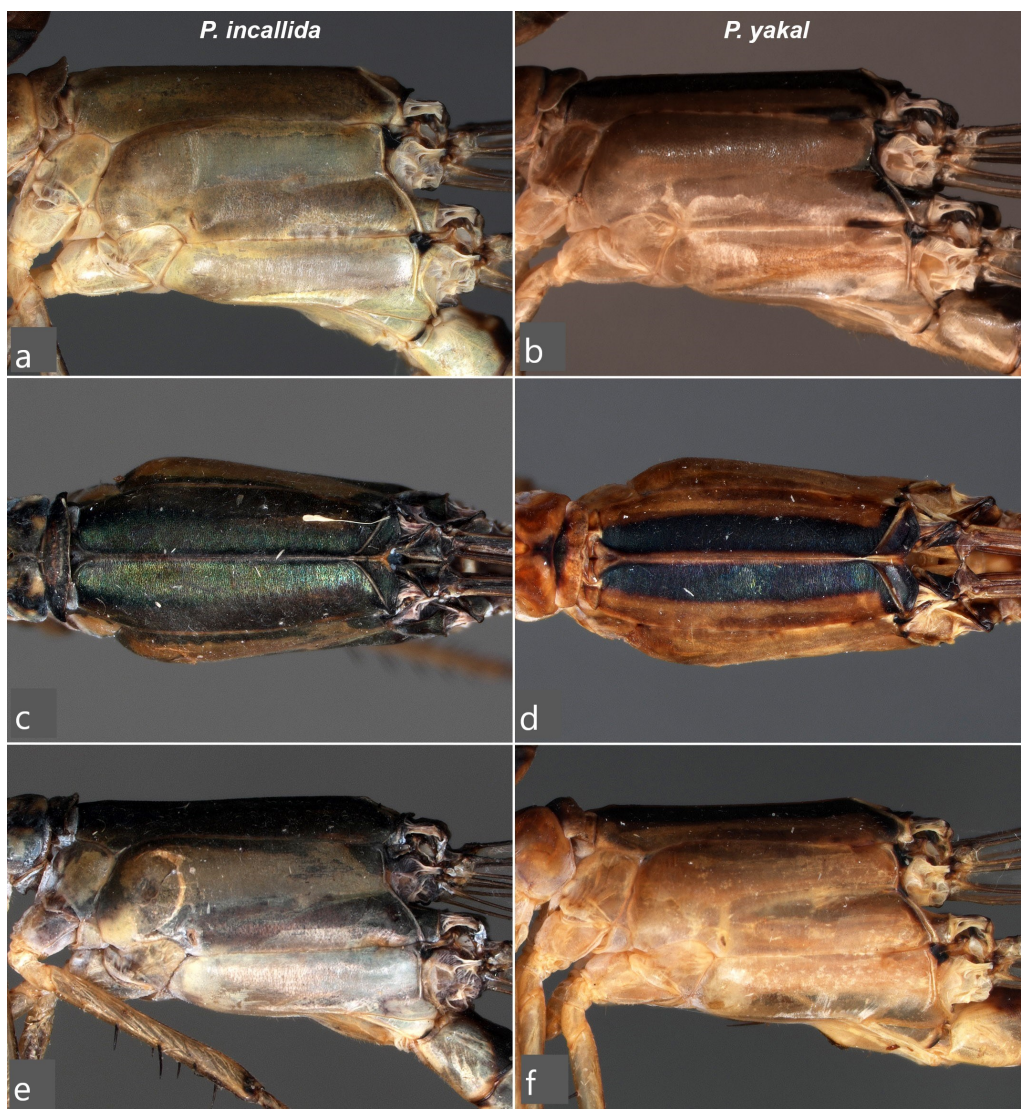

Figures 14a-f. Synthorax of incallida-group species: (14a) $P$. incallida male Luzon, lateral; (14b) P. yakal holotype, lateral; (14c) $P$. incallida female, dorsal; (14d) $P$. yakal paratype female, Leyte, dorsal; (14e) $P$. incallida female, lateral; (14f) P. yakal paratype female, Leyte, lateral. 


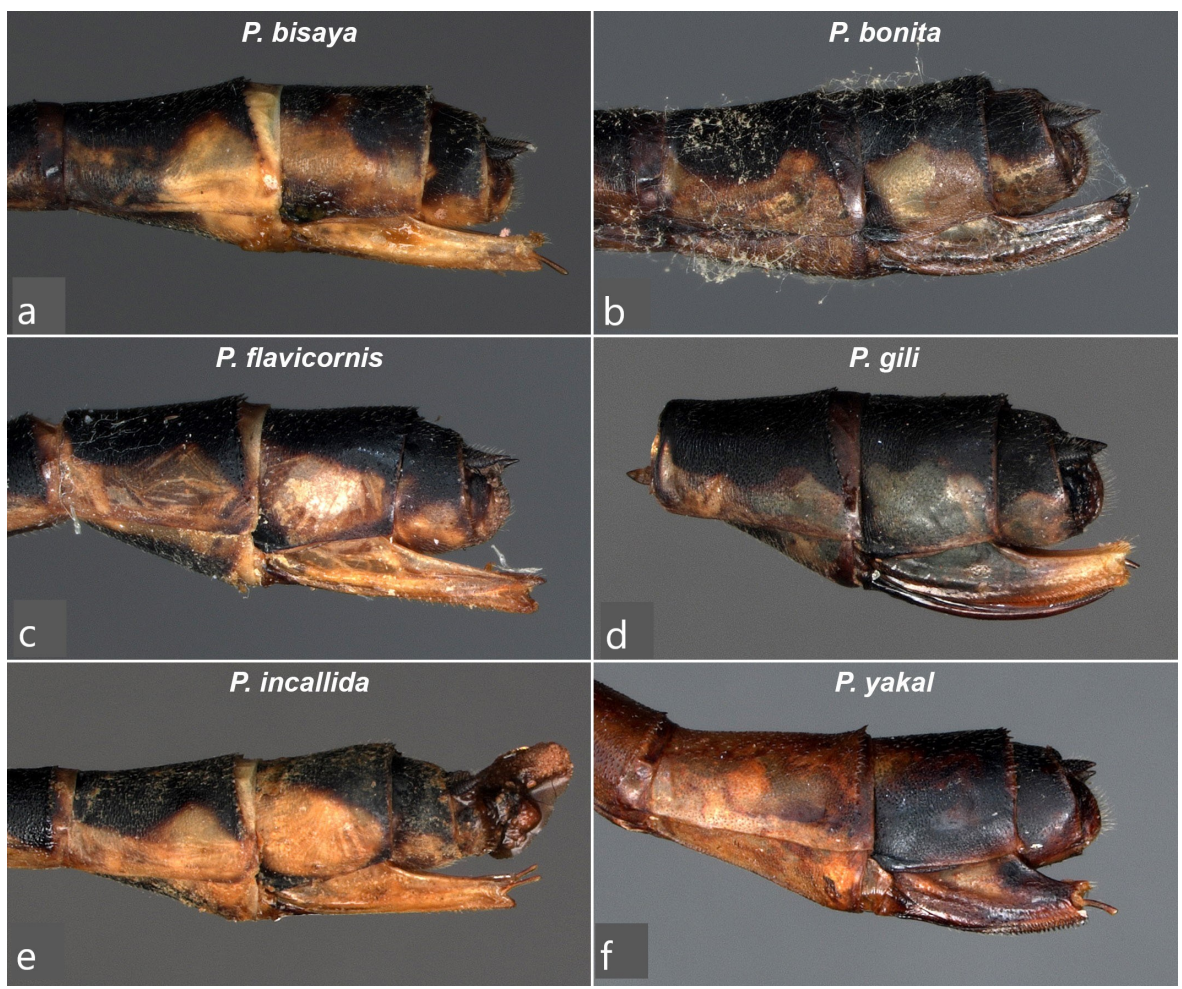

Figures 15a-f. Terminal abdominal segments of females, lateral view. $P$. bonita -group: (15a) P. bisaya paratype; (15b) P. bonita Los Baños; (15c) P. flavicornis Luzon; (15d) P. gili paratype. $P$. incallida-group: (15e) $P$. incallida; (15f) P. yakal paratype.

\section{P. bisaya}
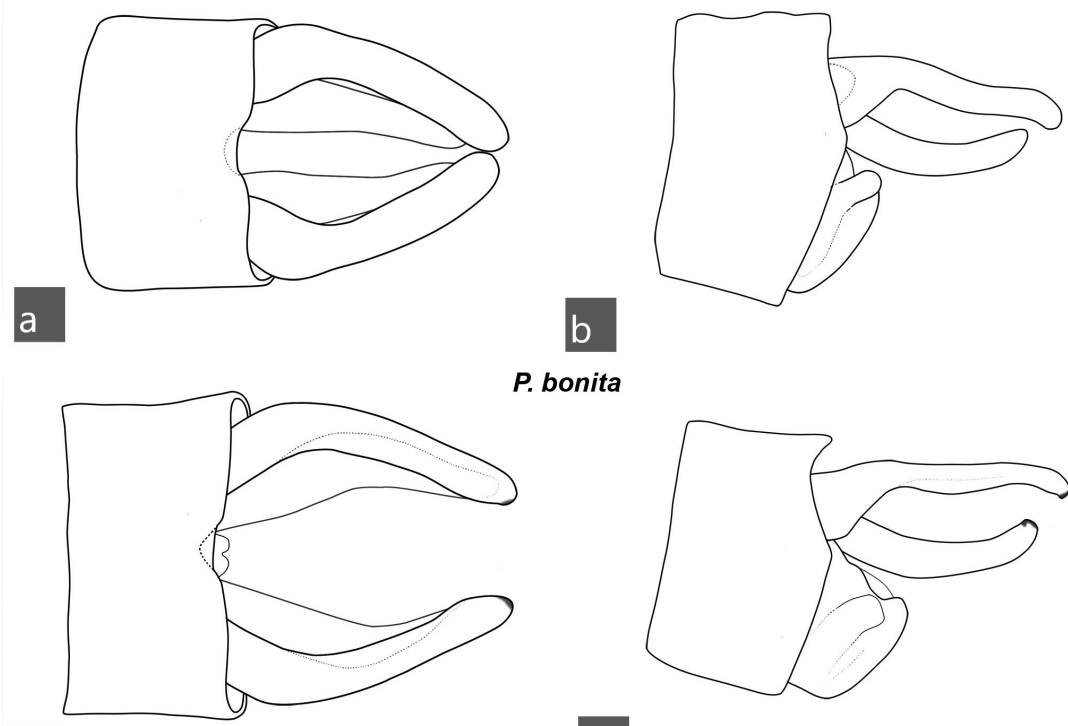

P. bonita

c

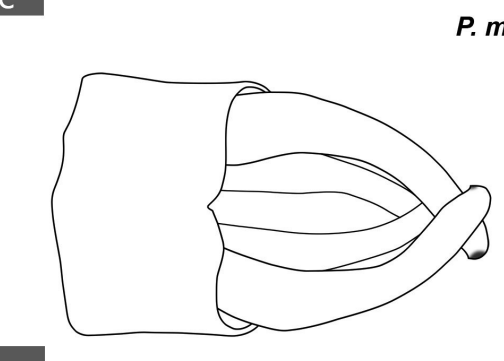

e

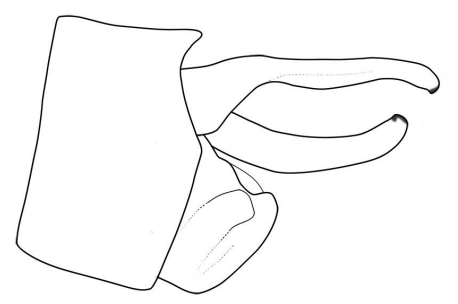

d

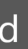

gbonita

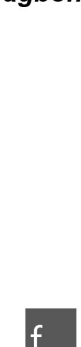

Figures 16a-f. Male anal appendages of bonita-group species. $P$. bisaya holotype: (16a) dorsal view; (16b) lateral view. P. bonita Los Baños: (16c) dorsal view; (16d) lateral view. $P$. muragbonita holotype: (16e) dorsal view; (16f) lateral view. 


\section{P. flavicornis}
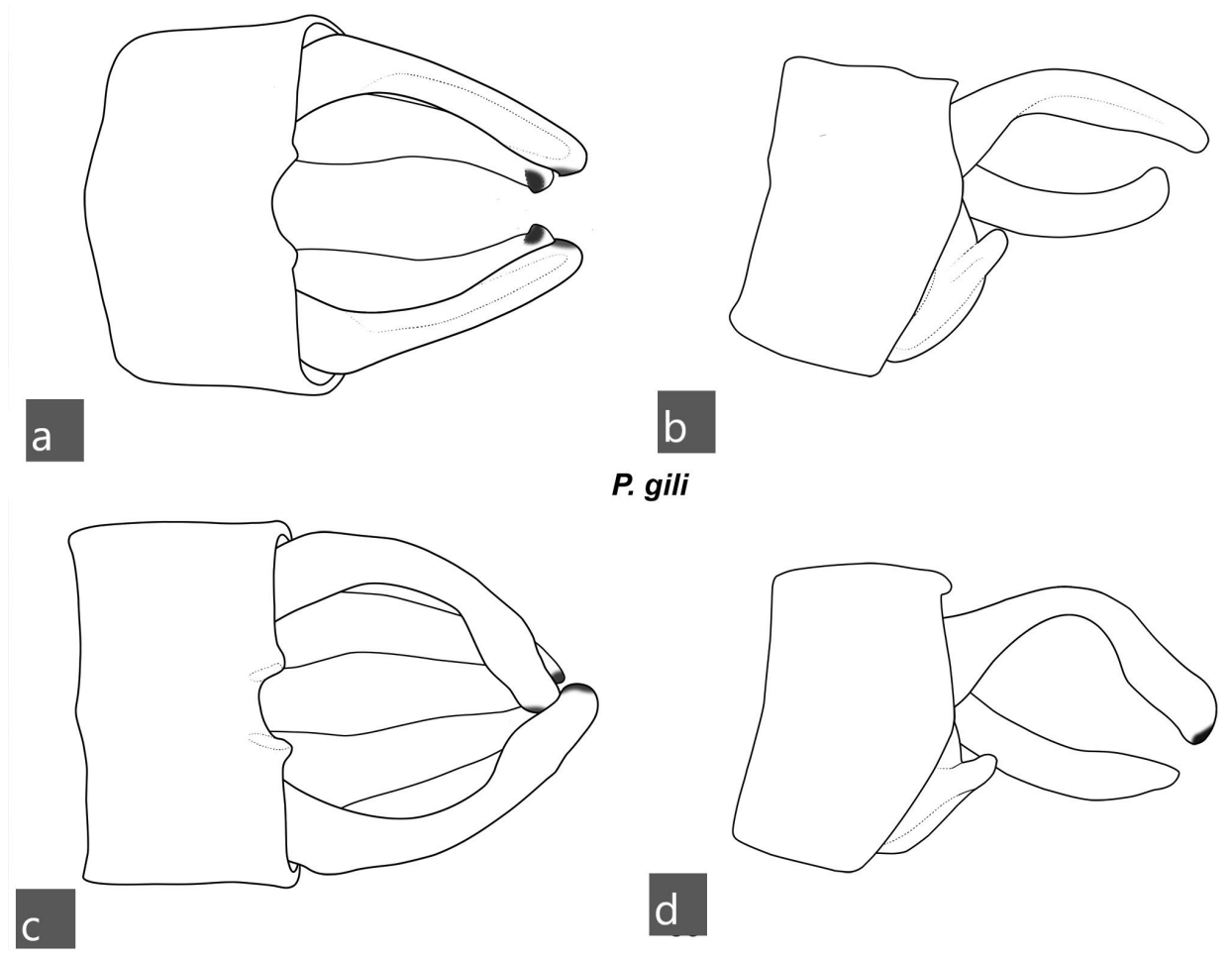

Figures 17a-d. Male anal appendages of bonita-group species. P. flavicornis male, Luzon: (17a) dorsal view; (17b) lateral view. P. gili holotype: (17c) dorsal view; (17d) lateral view.

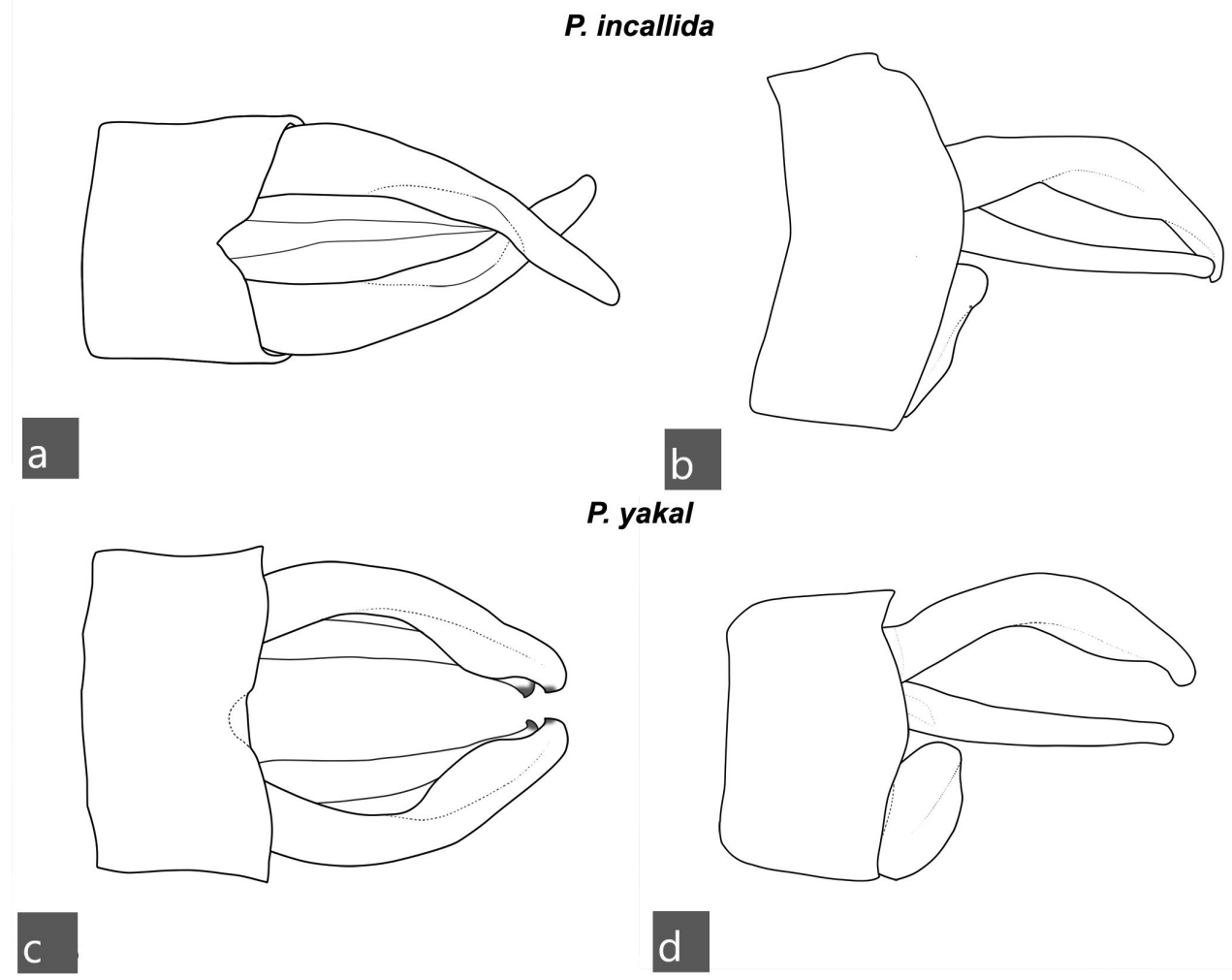

Figures 18a-d. Male anal appendages of incallida-group species. P. incallida male Luzon: (18a) dorsal view; (18b) lateral view. P. yakal holotype: (18c) dorsal view; (18d) lateral view. 
$2 \mathrm{fH}$, stream near mudspring, Mt. Makiling, Laguna, 1 iii 1988, in UPLB; $1 \mathrm{m \# ,} 1 \mathrm{fH}$, Mudspring, Mt. Makiling, Laguna, 30 xi 1987, leg. VPG, in UPLB; $1 \mathrm{~m} \#$, Mudspring, Mt. Makiling, Laguna, 3 i 1988, leg. V.P. Gapud, in coll. RJTV; $1 \mathrm{m \# ,}$ National Botanic Garden, Quezon, 22 iii 1986, in UPLB; 1 f\# (green form), Mt. Banahao, Kinabuhayan, Dolores, Quezon, 22

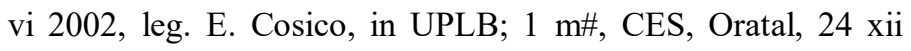
1985, in UPLB.

Diagnosis. The male of this species is orange, which easily distinguishes it from all others in the group except $P$. bisaya, $P$. muragbonita and $P$. flavicornis. It is distinguished from $P$. flavicornis by the lateral extremities of the posterior pronotal lobe not strongly produced to rear and from $P$. bisaya by lacking a sinuous lower lateral margin to the posterior pronotal lobe and from $P$. muragbonita by the much more deeply angulated lateral extremity of the posterior pronotal lobe.

Description of male (based on that from Los Baños 13 xii 1953). Head (Fig. 2c). Labium yellow. Mandible base mostly pale. Labrum orange, laterally narrowly black at base. Genae pale yellowish, continued along eye margin to level of base antenna. Anteclypeus largely pale, postclypeus largely black, orangish central area in upper part. Frons with distinct ridge; antefrons orange contiguous with orange streak running onto base of antenna. Scape and pedicel black and orangish brown, rest of antennae missing. Rest of the head matt black except small faint orange mark anterior to the anterior ocelli; faint transverse orange stripes either side of the ocelli, orange posterior margin of occiput with a narrow spur extending between the lateral ocelli; underside of head pale orangish.

Thorax. Prothorax largely pale orangish, posterior pronotal lobe black, large black lateral marks on middle pronotal lobe extending onto upper rear part propleuron, anterior carina of anterior pronotal lobe black except centrally. Anterior lobe of prothorax short. Posterior pronotal lobe, short, collar-like (Fig. $5 \mathrm{c}, 7 \mathrm{c}$ ), corners of free margin strongly angled. Synthorax (Figs 11c, 11d) almost entirely orange except for a narrow black stripe on each sides of the dorsal carina, broadened anteriorly (Fig. 11c). Legs same colour with dark brown spines. Wings hyaline with brown veins; Arculus very slightly distal to Ax2; Ac proximal to Ax2; petiolation ceases at ca level of Ac; R4 slightly proximal to subnodus; IR3 at subnodus; Px 14 (left) or 15 (right) in Fw, 13 (left) or 12 (right) in Hw. Pterostigma brown with largely pale frame and whitish margin, trapezoidal with costal side ca half-length of subcostal side.

Abdomen. S1-S2 pale orange, brown dorsally. S3-S10 brown dorsally, becoming darker on successive segments dorsum, paler laterally except S9 where dark with obscure pale marks. S3-S7 with paler basal annuli interrupted dorsally. Cerci (Figs 16c, 16d) black at base upper branch, rest pale. Upper branch cercus ca 1.5 times length of S10, broad at base but rapidly narrowing, in lateral view lower margin directed strongly up just after base to ca one third length, then whole running straight almost to apex, lower margin slightly convex in this section, turned slightly down subapically, rounded tip with small black tooth. In dorsal view cerci diverging for basal ca one third of their length, then converging, width almost constant after base, round tip. The lower branch robust, cylindrical, gently tapering, gently curved down from base then up to tip. Tip rounded with small dorsal black tooth, just before level of tips of cerci.

Measurements $(\mathrm{mm})$. Abdomen including anal appendages ca 49, Hw 28.

Variation. There is some variation in the markings of postclypeus and dorsum of the head, in some individuals the basal annuli on S1-7 are not evident.

Descriptive notes on female (based on that from Los Baños 13 xii 1953). Head (Fig. 2d). Very similar to male.

Thorax. Prothorax (Figs 5d, 7d, 10b) mottled dark and orangey brown, with pruinosity on propleuron, anterior pronotal lobe and laterally on middle lobe. Posterior pronotal lobe collarlike, middle portion ca twice wider than the lateral extremities, where square ended. Synthorax (Figs 12c, 12d) mesepisternum, mesepimeron, meseinfraepisternum mottled dark and brown, metepisternum same with pale areas lower, rest largely pale. Legs (tarsi missing on all, tibia missing left posterior leg, right posterior and left middle leg missing below coxa and trochanter respectively) mostly pale with darker areas on outer surfaces coxa, extensor surface tibia, spines dark brown. Wings as male except $16 \mathrm{Px}$ in Fw, $15 \mathrm{Px} \mathrm{Hw}$. Pterostigma frame mostly dark.

Abdomen. Very dark brown to black dorsally, brown laterally, paler basal annuli, narrowly interrupted dorsally, on S2 -S7. Cerci just shorter than S10, conical (Fig. 15b). Ovipositor largely orange brown, extending just beyond cerci.

Measurements (mm). Abdomen including ovipositor 47, Hw 33.

Distribution: Central Luzon around Laguna and mainland Quezon provinces

\section{Remark}

The specimen mentioned by Lieftinck (1957) was not studied and cannot be located in the RMNH collection. 
Pericnemis flavicornis Needham and Gyger, 1939

(Figs 3a, 3b, 6a, 6b, 8a, 8b, 10c, 13a, 13c, 13e, 15c, 17a, 17b)

Pericnemis flavicornis Needham \& Gyger 1939: 294-296, Figs. 262-264, 304 (original description both sexes, Baguio, Luzon).

Amphicnemis flavicornis (Needham \& Gyger 1939); Hämäläinen \& Müller 1997: 259-260.

Material (all from Luzon, the Philippines). $1 \mathrm{m \# ,} 1 \mathrm{fH}$, Sulong River, Madela, Quirino Province, 500-650m, 26-27 iv 1991, leg. Th. Borromeo, in RMNH; 1 m\#, Bial creek, Bungo River, Mt. Anaguao, Dinalungan, Aurora, 1000-1300m, 2-8 vii 1997, leg. Marcello Dusayen, in RMNH; $1 \mathrm{fH}$, Kasiguran, 30 viii 1915, G. Boettcher, in SMF; $3 \mathrm{m \# m \# ,} \mathrm{Mt.} \mathrm{Banahaw,}$ Kinabuhayan, Dolores, Quezon, 22 vi 2002, leg. VPG, in UPLB; $1 \mathrm{~m} \#$, same location, 22.vi.2002, leg. E. Cosico, in UPLB.

Diagnosis. This is a large orange species, the male is distinguished from all species in the group except $P$. gili by having the lateral extremities of the posterior pronotal lobe strongly but narrowly produced to rear and from $P$. gili by coloration and details of the posterior pronotal lobe and anal appendages.

Description of male (Based on that from Bial Creek 2-8 vii 1997). Head (Fig. 3a). Labium pale. Mandible base yellow and orange. Labrum black basally, orange towards free margin. Genae orange, continued along eye margin to level of antenna bases. Anteclypeus largely orange, postclypeus largely black, orangish basal streak. Frons with distinct ridge; mostly black. Scape and pedicel black with orangish streaks, rest of antennae brown. Rest of the head matt black except small faint orange marks on either side of ocelli, orange posterior margin of occiput; underside of head pale orangish.

Thorax. Pronotum black with obscure pale areas on anterior and middle lobe, propleuron obscurely dark and pale, black adjacent to middle pronotal lobe. Posterior pronotal lobe short (Figs 6a, 8a), collar-like, its outer margin slightly upcurved, lateral extremities abruptly produced to rear (Fig. 8a). Synthorax - mesepisternum largely dark metallic green with orangish areas laterally (Fig. 13a), rest orangish with some obscure darker areas. Legs orange with dark spines. Tarsi without denticle. Wings hyaline with dark brown veins; Arculus slightly distal to Ax2; Ac proximal to Ax2; petiolation ceases at ca level of Ac; R4 before subnodus; IR3 just distal to subnodus; the two apparently fused in right Fw. 15 (left) or 16 (right) Px in Fw, 15 (left) or 14 (right) Px in Hw. Pterostigma brown with pale margins, trapezoidal.

Abdomen. S1-S6 dark above, becoming darker on successive segments, pale laterally with basal pale annulus interrupted dorsally. S7 similar but distal ca two-thirds darker laterally. S8 mostly black with basal lateral subtriangular yellow mark. S9 black. S10 black dorsally, yellowish lower laterally. Cerci (Figs 17a, 17b) black at base upper branch, rest pale brownish except dark tips both branches, a little more than the length of S10. Upper branch broad in basal ca one-fifth, directed up in this part, upper margin forming a gentle arc to apex, lower margin running almost straight after basal ca one-fifth almost to rounded apex, where very slightly down-turned. Lower branch little shorter than upper branch, robust, cylindrical in crosssection, gently curved toward upper branch, its apex rounded with small blunt black ventral tooth.

Measurements (mm). Abdomen including anal appendages 50, Hw 30 .

Variation: The basal half of labrum is blackish brown in some individuals. The posterior pronotal lobe is sometimes more elongate laterally, with a distinctly rounded lateral margin. IR3 is sometimes at the subnodus or fused with R4 at the subnodus.

Description of female (based on that from Sulong River 26-27 iv 1991). As male except as noted. Head (Fig. 3b). Mandible bases and genae yellowish, labrum entirely orangish except basal lateral corners. Short pale streak running from antenna bases to ridge of frons, pale mark rear of occiput with narrow spur between lateral ocelli.

Thorax. Prothorax (Figs 9b, 8b, 10c) with pale areas much more extensive. Lateral extremities of posterior pronotal lobe much less produced than male, rounded (Fig. 8b). Synthorax dark metallic green narrowly on either side of middorsal carina only, rest of mesepisternum brown with small paler streaks at mesepleural suture. A brown area along upper part of mesepimeron, extended beside antealar carina, remainder of synthorax bluish with some obscure darker marks. Legs mostly pale. Wings with $16 \mathrm{Px}$ in Fw, 15 (left) or 14 (right) Px in Hw, pterostigma paler than male.

Abdomen. S1-S2 black dorsum, bluish laterally. S8-S10 black, pale lower laterally, this very restricted on S10 (Fig. 15c). Cerci short, conical. Ovipositor largely pale, extending a little beyond tips of cerci.

Measurements (mm). Abdomen including ovipositor 43, Hw 31.

Distribution: Central Luzon around Aurora and Quirino provinces 


\section{Pericnemis bisaya spec. nov.}

(Figs 2a, 2b, 5a, 5b, 7a, 7b, 10a, 11a, 11b, 12a, 12b, 15a, 16a, 16b)

Amphicnemis sp. (cf bonita); — Hämäläinen \& Müller 1997: 259, 278 (Cebu, Negros, Panay, note 36).

Holotype m\#, "Philippines, Cebu Id, Minglanilla, Camp 7, 21 22.v.1991, M. Hämäläinen”, in RMNH.

Paratypes (all from Cebu, in RMNH). $5 \mathrm{m \# m \# ,} \mathrm{Hagnum,} 14$ iv 1999, leg. T. Borromeo; 1 m\#, Hagnum, 14 iv 1999, leg. J. Mondarte; $1 \mathrm{m \# ,} \mathrm{Camp} \mathrm{7,} \mathrm{Minglanilla,} \mathrm{12.ii.1999,} \mathrm{leg.} \mathrm{T.}$

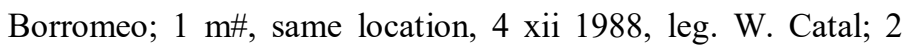
f\#f\#, same location, 21-22 v 1991, leg. R.A. Müller; 3 f\#f\#, same location, 21-22 v 1991, leg. M. Hämäläinen; 2 f\#f\#, same location, 11 iii 1999, leg. T. Borromeo; $1 \mathrm{fH,} \mathrm{same} \mathrm{location,} 10$ iii 1999, leg. T. Borromeo; $1 \mathrm{fH,} \mathrm{same} \mathrm{location,} 9$ iii 1999, leg. T. Borromeo.

Other material (all in RMNH unless otherwise stated). $1 \mathrm{m \# ,} 1$ f\#, Danao Lake "in mossy forest", Patag, Silay, Negros, 12001300m, 21-22 v 1996, leg. A. Buenafe; 1 f\#, Asia River, Mt. Canlaon, Murcia, Negros, ix 1989, leg. A. Buenafe; 1 f\#, Mt. Talinis, Negros Oriental, 400m, 14 vii 1987, leg. Treadaway; 1 f\#, Kidnawan Creek, Baloy Mts., Inca, Lumbanao, Iloilo Province, Panay, 20-30 xi 1994, leg. A. Buenafe"; 1 m\#, 9 f\#f\#, Mt. Clara, Aningalam, San Remigio, Antique, Panay, 600650m, 28 vii-10 viii 1996, leg. A. Buenafe; 5 m\#m\#, 4 f\#f\#, Atipohan River, Mt. Clara, Aningalam, San Remigio, Antique,

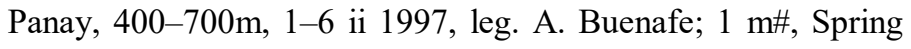
Camp, Tambanban River, Yakal, Tandang Sora, Sigaboy, Davao Oriental, Mindanao, 800m, 5-14 x 1996, leg. A. Buenafe"; 1 m\#, Butac, La Union, San Isidro, Davao Oriental, Mindanao, 8 iii 2009, leg. H. Cahilog, in coll. RJTV; $3 \mathrm{fHf \# ,}$ Camp 7, Minglanilla, Cebu, 8 ix 2009, leg. RJTV, in coll.

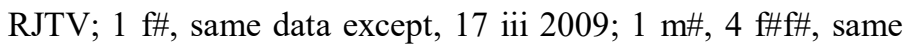
data except 18 iii 2009.

Etymology. A noun in apposition, bisaya, the main dialect in the central Visayas.

Diagnosis. The sinuous lower lateral margin of posterior pronotal lobe of the prothorax is diagnostic in males.

Description of holotype male. Head (Fig. 2a). Labium yellow, mandible bases yellow. Basal half labrum dark, rest orange. Genae yellowish, this continued narrowly along eye margin to level of antennae. Postclypeus black, anteclypeus pale, dark centrally in upper part. Frons with distinct ridge; anterior part mostly yellow, posterior part black. Rest of the head matt black except for pale vertical streak on front of scape, pale base of pedicel extending as streaks on anterior and posterior faces, small yellow ovoid streak between lateral ocelli and antenna, yellow hind margin of occiput.

Thorax. Prothorax (Figs 5a, 7a) with anterior lobe short and erect, yellow with anterior carina black, middle lobe simple, yellow, posterior lobe black, short, collar like with free margin slightly up-turned, laterally corners slightly produced as flat rearward processes more produced on left than on right, lower lateral margin sinuous (Fig. 7a). Propleuron yellow. Synthorax (Fig. 11a, 11b) entirely yellow except much of mesepisternum black, this occupying almost the entire width adjacent to the prothorax, narrowing until ca one third length of mesepisternum, them more gradually to antealar triangle, where occupying ca half width of dorsum of mesepisternum; middorsal carina yellowish, antealar triangles with black marks near wing bases. Legs with coxa, trochanter and femur yellow. Tarsi without denticle. Wings hyaline with dark brown veins. Arculus just after Ax2, Ac proximal to Ax2, petiolation ceases at ca level of Ac, R4 before subnodus, IR3 just after subnodus. 15 in Fw, 14 in Hw. Pterostigma grey brown with prominent pale margin, trapezoidal, with subcostal side longer than costal side, covering ca one underlying cell.

Abdomen. S1-S2 yellow laterally, brownish dorsally. S3S7 dorsally brown, laterally pale, narrow pale basal annulus interrupted dorsally. S8 black, yellowish to sides. S9 black. S10 black, pale lower laterally. Cerci (Figs 16a, 16b) black to very dark brown at base, rest pale brownish, longer than S10. Upper branch broad in basal ca one-fifth, in lateral view lower margin directed up in this part, upper margin almost flat, then whole directed slightly downward, almost parallel sided to rounded, darkened tip. In dorsal view upper branches gently curved toward each other. Small black inward and ventrally directed tooth at apex, best seen in ventral view. Lower branch just shorter than upper branch, robust, cylindrical in cross section, gently curved, its tip rounded with tiny blunt black dorsal tooth.

Measurements (mm). Abdomen including anal appendages 49.5, Hw 29.

Variation: Some males from Panay and all from Negros are green. It is not known if the Cebu population includes both green and orange form males, since only specimens of the latter form are available in collections and seen in the field.

Description of female (based on one from Minglanilla, 11 ii 1999). Head (Fig. 2b). Labium whitish. Labrum orange with 
black lateral and central marks at base. Genae yellow, this extended along eye margin to ca level of antenna. Anteclypeus yellowish with brown marks. Postclypeus black. Frons with distinct ridge, antefrons mostly yellow, postfrons black. The rest of the head black with metallic reflection except for yellow streak at antenna base, yellow streaks anteriorly and posteriorly on otherwise dark brown scape (rest on antenna missing), small yellow marks outside of ocelli. Rear of occiput yellowish, underside of head pale.

Thorax. Prothorax (Figs 5b, 7b, 10a) bluish-green with obscure yellowish blots, anterior pronotal lobe black along anterior carina. Posterior pronotal lobe broad, simple collarlike. Synthorax (Figs 12a, 12b) mainly bluish, mesepisternum olive, poorly defined areas of similar colour by antealar carina on mesepimeron and metepisternum. Wings with $16 \mathrm{Px}$ in Fw, 14 (left) or 15 (right) Px in Hw. Legs with coxa bluish, rest pale with poorly defined darker marks on femur, spines dark.

Abdomen. Black dorsally, pale lower laterally, incomplete basal pale annuli on S3-S7. Boundary between black and pale irregular on S8-10 (Fig. 15a). Cerci short, pointed, pale ovipositor extending just beyond tips of cerci.

Measurement (mm). Abdomen including ovipositor 51, Hw 32.

Distribution: Cebu, ?Negros and ?Mindanao island

Remarks: The Mindanao, Negros and Panay populations are tentatively assigned to this species. The Panay population has both orange (teneral) and green forms. Only one male is available from Negros, and that is a green form. The lack of significant structural difference has justified our placement of the three populations under one species.

\section{Pericnemis muragbonita spec. nov.}

(Figs 2e, 2f, 5e, 5f, 11e, 11f, 16e, 16f)

Amphicnemis sp. (cf. flavicornis); — Hämäläinen \& Müller 1997: 260, 278 (Samar, note 37).

Holotype m\#, "Philippines, Samar Id, Samar, Hinabangan, Bagakay, San Isidro, 100-200m, 29.viii - 20.ix.1996, Alex Buenafe", in RMNH.

Paratype $1 \mathrm{~m} \#$, San Isidro, Bagakay, Hinabangan, Samar Province, Samar, 100-200m, 29 viii-20 ix 1996, leg. A. Buenafe, in RMNH.

Other material. $1 \mathrm{~m} \#$, Arizona, Hinabangan, Samar Province, Samar, 100-200m, 29 iii-6 iv 1997, leg. R.A. Müller, in RMNH; 1 m\#, Catbalogan. Samar, 21 iv 1915, leg. G.
Boettcher, in SMF.

Etymology. A noun in apposition formed from bonita and murag, a word from the Cebuano language meaning similar, in reference to its close resemblance with $P$. bonita.

Diagnosis. The male is easily separated from all other species in the group except for $P$. bonita and $P$. bisaya by its coloration and having a posterior pronotal lobe with lateral extremities not strongly produced to rear. It is separated from $P$. bonita and $P$. bisaya by almost parallel sided metallic band on the dorsum of the synthorax as well as details of the structure of the posterior pronotal lobe.

Description of holotype male. Head (Figs 2e, 2f). Labium whitish. Mandible base pale. Labrum brownish black in basal half, anterior half yellowish. Genae pale, this colour continued narrowly along anterior eye margin to antennae bases. Anteclypeus pale, centrally brownish above. Postclypeus black. Antefrons pale, postfrons black. Rest of head black with metallic green reflection, except for pale markings at antennae bases, pale anterior and posterior stripes on scape and pedicel, brownish remainder of antennae, faded elongate yellow streak between antennae and lateral ocelli, yellow hind margin of the occiput, medially extended as narrow spur terminating between the lateral ocelli.

Thorax. Prothorax (Figs 5e, 5f) with anterior pronotal lobe yellow except for black anterior margin, short, erect. Median pronotal lobe yellow. Posterior lobe black, collar-like: gently up curved centrally at free margin, free margin slightly concave to both sides of center, angulated at lateral extremities (Fig. 5f). Synthorax (Figs 11e, 11f) with dorsal half of mesepisternum dark metallic green, mid dorsal carina yellow. Remainder of synthorax yellow, becoming paler lower down, yellowish ventrally. Legs with coxa, trochanter, femur and tibiae yellowish, tarsi with black tip, without denticle. Wings hyaline with brown veins. Arculus just distal Ax2, Ac near Ax2, petiolation ceases at the level of arculus. R4 just before subnodus; IR3 at subnodus. Fw with 16 (left) or 15 (right) Px, Hw with 14Px. Pterostigma almost square, grey with prominent pale margin, costal side a little shorter than subcostal, covering one underlying cell.

Abdomen. S1 yellow, brownish dorso-apically. S2 yellow, brownish dorsum. S3-S7 black above, pale lower laterally and pale basal annulus, interrupted dorsally. S8 black dorsally, pale laterally. S9 black, pale behind posterior carina. S10 black dorsally, pale lower laterally. Cerci (Figs 16e, 16f) yellowish except brownish area on basal ca one third of upper branch. Upper branch longer than S10, flattened; in lateral view basal ca 
one-third upper almost flat along upper margin, lower margin directed upwards, after basal ca one third upper and lower margins almost parallel, whole slightly sinuous, directed gently down to rounded tip. In dorsal view curved gently inward from base; a small black incurved tooth present interiorly at apex. Lower branch cylindrical in cross-section, gently curved along its entire length in lateral view, gently inwardly directly in ventral view, apex black with small inwards directed black tooth.

Measurements (mm). Abdomen including anal appendages 45, Hw 28.

Variation in paratype. The labrum is sometimes more extensively yellow.

Female. Unknown.

Distribution: Samar Island

Pericnemis gili spec. nov.

(Figs 3c, 3d, 6c, 6d, 8c, 8d, 10d, 13b, 13d, 13f, 15d, 17c, 17d)

Amphicnemis sp.n.; — Hämäläinen \& Müller 1997: 260, 278 (Luzon, note 39).

Holotype m\#, "Philippines, Luzon Id, Quirino Prov., Sierra Madre, Sulong River, 550m, 13.v.1990, Th. Borromeo Sr", in RMNH.

Paratypes (all in RMNH unless otherwise stated, all from Luzon). $1 \mathrm{~m} \#$, Sulong River, Sierra Madre, Quirino Province, 550m, 13 v 1990, leg. T. Borromeo Sr; $2 \mathrm{fHfH,} \mathrm{same} \mathrm{data} \mathrm{except}$ 14 v 1990; $1 \mathrm{fH}$, same data except 15 v 1990; $1 \mathrm{fH}$, same location and collector, 500-650m, 26-27 iv 1991; $1 \mathrm{fH}$, Dalton Pass, Sta Fe, Nueva Viscaya Province, $800-1200 \mathrm{~m}, 25-30$ vi 1989, leg. A. Gorostiza; 1 m\#, Paete, 28 vi 1916, leg. G. Boettcher, in SMF.

Etymology. Gili, a noun in genitive case, named after John Ronel S. Gil, born in Virac, Catanduanes, on May 20, 1989, now Educator at Dubai Aquarium and Under Water Zoo.

Diagnosis. This is a blue species. The red pterostigma and elongate, flat and twisted, strongly produced lateral extremities of the posterior pronotal lobe in males and strongly curved upper branch of the cercus are characteristic and serves to distinguish them from those of all other species of the group.
Description of holotype male. Head (Fig. 3c). Labium mostly whitish. Mandible bases, genae blue, this extended upwards to level of antenna bases. Labrum mainly blue except black basolateral marks. Anteclypeus blue, black centrally adjacent to labrum. Postclypeus black. Frons with distinct ridge, black with transverse blue stripe that is interrupted centrally. Blue streak on anterior face of scape, pale ring on top of pedicel. Rest of dorsum of head metallic black, extensive bluish areas on underside.

Thorax. Prothorax (Figs 6c, 8c) with propleuron blue, anterior pronotal lobe blue except black anterior carina; middle pronotal lobe with narrow pale marking dorsally, posterior pronotal lobe greenish metallic black, collar-like, lateral extremities produced as a narrow spur extending caudad (Fig. 8c). Synthorax (Fig. 13b): mesepisternum dark metallic green, mesostigmal plates blue. Mesepimeron blue, upper anterior part black, narrowing toward wing bases, small black excision from mesepleural suture near wing bases. Upper part meseinfraepisternum black, this extended lower anteriorly, rest blue. Most of rest of synthorax blue, with a small brown patch near the wing bases just above the metapleural suture on the metepisternum, black mark on metinfraepisternum. Legs (right anterior missing) with coxae blue, trochanters blue-white. Femora with black extensor surfaces, rest grey and pale, tibiae with black flexor surfaces, rest grey and pale; tarsi pale, black at joints, claws brown, black tips without denticle. Wings hyaline with dark brown veins. Arculus beyond Ax2; Ac near Ax2; petiolation ceases at the level of arculus; R4 just before subnodus; IR3 at or just after subnodus. $13 \mathrm{Px}$ Fw, 12 in Hw. Pterostigma reddish, darkened centrally, trapezoidal, covering just less than one underlying cell.

Abdomen. S1-2 black dorsum, blue laterally. S3-S7 brownish dorsally, becoming darker apically and on progressive segments, paler laterally, incomplete pale basal annuli present. S8 black except for pale areas lower laterally; S9 black. S10 black, largely pale laterally. Distal margin of dorsum S10 slightly excised centrally, this with margins raised. Cerci (Figs 17c, 17d) yellow, dark at base, longer than S10. Upper branches of cerci strongly arched in lateral view (Fig. 17d), narrowing from base to a minimum at the top of the arch, somewhat expanded subapically, slightly hooked down at apex, where black dorsally; a tiny black ventral tooth is present. In dorsal view upper branch curved inward (Fig. 17c). Lower branch reaches tip of upper branch, robust, cylindrical in cross section, slightly swollen subapically, then tapered to apex with inwards directed black tooth.

Measurements (mm). Abdomen including anal appendages 48, Hw 28. 
Description of female. Similar to male except where noted. Head (Fig. 3c). Labrum yellowish, grey basally. Pale markings anteclypeus yellowish.

Thorax. Prothorax (Figs 6d, 8d, 10d) with posterior pronotal lobe raised to rear, lateral extremities not produced to rear but extending downwards (Fig. 8d), almost square ended. Synthorax (Figs 13d, 13f) with mesepisternum occupied centrally by broad bronzy black mark with gently curved margin, widest at ca two-thirds length, remainder greenish, antealar triangles bronzy black. Remainder of synthorax laterally bluish except small black mark on metepisternum, based on metapleural suture near antealar carina, black mark on mesinfraepisternum in upper corner near prothorax, another in upper rear corner extending slightly onto adjacent part mesepimeron. Venter pale bluish. Wings with 15 (left) or 16 Px in $\mathrm{Fw}, 14 \mathrm{Px}$ in $\mathrm{Hw}$, pterostigma brownish with pale margin.

Abdomen. Cerci short, conical. Ovipositor bluish at base, yellowish toward apex, extending just beyond tips of cerci. Terminal segments shown in Fig 15d.

Measurements (mm). Abdomen including ovipositor 46, Hw 32.5 .

Distribution: Central and Northern Luzon

\section{Pericnemis bonita-group spec. indet. A}

Material examined. $1 \mathrm{fH}$, Pinagtahican, Pinagsangaan, Palanan, Isabela, Luzon 12-20 ix 2008, leg. RJTV, in coll. RJTV.

Remarks. The coloration of this specimen resembles that of $P$. gili, but it structurally distinct from that species. The Palanan specimen has a simple collar-like posterior pronotal lobe without the distinct spurs at the lateral extremities that are present in $P$. gili. More material is needed, especially male specimens, to clarify the status of this population.

Pericnemis bonita-group spec. indet. B

Amphicnemis cf. bonita; - Villanueva 2010: 8 (Sibulan Watershed, Polillo).

Material examined. $1 \mathrm{m \# ,} 8 \mathrm{f} \mathrm{fH}$, Sibulan Watershed, Sibulan, Polillo Municipality, Polillo Is., Quezon province, 1 iv 2010, leg. local collector, in coll. RJTV.

Remarks. This taxon closely resembles $P$. bonita but differs in some respects. We refrained from describing it until more material is available.

\section{Pericnemis bonita-group spec. indet. C}

Materials examined. $3 \mathrm{~m} \# \mathrm{~m} \#, 2 \mathrm{fH} \mathrm{f}$, Himaao River, Bungcao Curry, Mt. Isarog, Pili, Camarines Sur, Luzon, 200-400m, 4-15 viii 1997, Leg. C. Nazareno, in RMNH; 1 m\# (RMNH), Mt. Isarog, Pili, Camarines Sur, Luzon, 800m, 27 iv 1965, leg. H.M. Torrevillas, in RMNH.

Remarks. This taxon closely resembles $P$. bonita but differs in some respects. We refrained from describing it until more material is available for both this population and for P. bonita. A molecular analysis will be helpful in clarifying the taxonomic status of this population.

\section{Pericnemis incallida-group}

\section{Pericnemis incallida Needham \& Gyger, 1939}

(Figs 4a, 14b, 9a, 9b, 10e, 14a, 14c, 14e, 15e, 18a, 18b)

Pericnemis incallida Needham \& Gyger, 1939: 291-292, Figs. 254, 255, 305 (original description male, Luzon and Samar); Needham \& Gyger 1941: 148 (description female, ?Luzon).

Amphicnemis incallida (Needham \& Gyger, 1939); Hämäläinen \& Müller 1997: 260, 278, (Luzon, note 40); Ramos \& Gapud 2007: 56.

Material examined (all in RMNH, all from Luzon). $1 \mathrm{m \# ,}$ Ternate, Cavite Province, 7 iii 1989, leg. C. Treadaway \& T. Borromeo; 1 f\#, Pared River, Napato, San Miguel, Baggao, Cagayan Province, 200-600m, leg. A. Buenafe \& A. Gorostiza; 1 fH, Barangay Binugauan, Santa Maria, Flora, Apayao Province, 200-400m, 14-20 iv 1997, leg. C. Nazareno.

Diagnosis. The male can be distinguished from all others except for $P$. yakal by the characters given in the key. It is separated from $P$. yakal by the shape of the posterior pronotal lobe (compare Figs 9a and 9c) and the tubercle of the shaft of the genital ligula bluntly triangular rather than a barely discernible ridge or absent.

Description of male (based on that from Ternate, 7 iii 1989). Head (Fig. 4a). Labium pale, brownish distally. Genae and mandible bases largely pale, small dark spot on mandible bases near labrum. Labrum black with yellow anterior half, pair of well separated yellow marks basally. Anteclypeus pale with pair of poorly defined brown spots, postclypeus black. Frons with distinct ridge, antefrons pale, rest black, pale color on genae extended narrowly beside eye margin to beyond antennae bases. 
Rest of head black with metallic greenish reflection, except for pale streaks on antennae bases, whitish rings top of pedicel, variegated pale and dark pedicel (rest of antennae missing), faint bluish spots between ocelli and eye margins, yellowish streak rear of occiput.

Thorax. Prothorax (Fig. 9a) pale greenish blue mottled with darker specks and paler areas, dark central mark middle pronotal lobe adjacent to anterior pronotal and lateral portion of posterior lobe. Anterior pronotal lobe short and erect. Middle pronotal lobe simple. Central part of posterior pronotal lobe deep, fan-shaped, free margin up-curved; laterally free margin curved forwards, reaching minimum ca one third that of central part, then curved back to rear to form rounded protruding corner. Synthorax (Fig. 14a) largely bluish green, mesepisternum with orange tint. Legs pale with narrow black stripe on extensor surface posterior femur, spines black, tarsal claws with small denticle. Wings hyaline with dark brown veins; Arculus just distal to Ax2; Ac proximal Ax2; petiolation ceases at ca level of Ac; R4 before subnodus; IR3 at subnodus.14 Px in Fw, 12 Px in Hw. Pterostigma brown with yellow margin, trapezoidal with costal side ca half-length of subcostal side.

Abdomen. Brown above, paler laterally. S3-S7 with pale basal annulus interrupted dorsally, S2-S6 with small dorsal lateral subapical yellow streak. S7-S9 black dorsum, paler laterally, boundary between two irregular and obscure but pale area becoming more extensive on successive segments. S10 yellowish, dark dorsally. Cerci (Figs 18a, 18b) largely blackish, nearly twice the length of S10. Upper branches cerci in dorsal view running straight along inner margin in basal half then gently curving inwards, gently inwards curved from shortly after base along outer margin. In lateral view upper branch hooked abruptly downwards after half-length along upper margin, down turned more gently from ca one-quarter length along lower margin, apex with small tooth. Lower branch cylindrical, tapering slightly from base to rounded black tip, in dorsal view curved inward distally. Genital ligula with the tubercle on the shaft bluntly triangular.

Measurements (mm). Abdomen including anal appendages 58, Hw 34 .

Descriptive notes on female. Similar to male except where noted. Head (Fig. 4b). Labrum lacking basal pale marks.

Thorax. Prothorax (Figs 9b, 10e) with anterior pronotal lobe bluish except for black anterior margin; median pronotal lobe bluish with black areas. Posterior lobe bluish, darker laterally, collar-like centrally with free margin gently upcurved, narrowing laterally but lateral extremities produced somewhat to rear. Synthorax (Figs 14c, 14e) dark metallic blackish green dorsally, mostly bluish laterally. Wings with 15 Px in Fw, 14 Px in Hw, pterostigma with faint whitish margin.

Abdomen. Dorsum black, no subapical pale marks, boundary between black dorsal marks and yellowish sides everywhere well defined, S10 only narrowly yellow lower laterally (Fig. 15e). Cerci shorter than S10, pointed. Ovipositor yellowish, extending to ca level of tips of cerci.

Measurements (mm). Abdomen including ovipositor 49, Hw 32.5 .

Distribution: Central and Northern Luzon

\section{Remark}

The Samar records mentioned by Hämäläinen \& Müller (1997) is referred to $P$. yakal spec. nov

\section{Pericnemis yakal spec. nov.}

(Figs 1b, 4c, 4d, 9c, 9d, 10f, 14b, 14d, 14f, 15f, 18c, 18d)

Amphicnemis sp. (cf. incallida); - Hämäläinen \& Müller, 1997: 260, 278 (Samar, Leyte, Mindanao, note 41).

Holotype m\#, Spring Camp, Tabanban River, Yakal, Tandang Sora, Sigaboy, Davao Oriental, Mindanao 800m, 5-14 x 1996, leg. A. Buenafe, in RMNH.

Paratype. $1 \mathrm{~m} \#$, Meme River, Tago, Surigao del Sur, Mindanao, 100-300m, 12-18 iv 1996, leg. A. Buenafe \& A. Gorostiza, in RMNH.

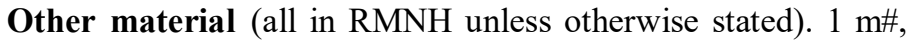
San Rafael, Eastern Samar Province, Samar, 50-180m, 21-24 iv 1992, leg. T. Borromeo Jr; 8 f\#f\#, Arizona, Hinabangan, Samar Province, Samar, 100-280m, 29 iii-6 iv 1997, leg. R.A. Muller; $1 \mathrm{fH}$, same location, 100-200m, 29 viii-20 ix 1996, leg. A. Buenafe; $1 \mathrm{fH}$, same location, 100-280m, 5-12 v 1997, leg. A. Buenafe; 1 f\#, Mt. Sohoton, Basey, Samar, 16 x 1994, leg. T. Borromeo Sr.; $1 \mathrm{f}$, San Isidro, Western Samar Province, Samar, 18 x 1994, leg. T. Borromeo; 1 f\#, Mt. Bolocaue, Hilusig, Leyte, 500m, 7 viii 1997, leg. C.G. Treadaway; 1 fH, same location, 600m, 17 v 1988, leg. unknown; $1 \mathrm{fH}$, same location, 600m, $2-$ 14 v 1986, leg. T. Borromeo; 1 f\#, Sta. Cruz, Leyte, 14 x 1915, leg. G. Boettcher, in SMF; $3 \mathrm{fHf \# ,} \mathrm{Alog} \mathrm{River,} \mathrm{Mt.} \mathrm{Hamiguitan,}$ Mati, Davao Oriental, Mindanao, 18 iii 2007, leg. RJTV, in coll. RJTV; 1 m\#, Tinagong Dagat, Mati, Davao Oriental, Mindanao, 27 viii 2008, leg. H. Cahilog, in coll. RJTV; 1 f\#, Danao Daku, Ferdinand, Loreto, Dinagat, 22 vi 2008, leg. RJTV, in coll. 
RJTV.

Etymology. Yakal, a noun in apposition. Refer to a local name of Shorea astylosa, one of the tree species that the species used its tree holes as breeding habitat.

Diagnosis. The male can be distinguished from all others except for $P$. yakal by the characters given in the key. It is separated from $P$. yakal by the shape of the posterior pronotal lobe (compare Figs 9a and 9c) and the tubercle of the shaft of the genital ligula a barely discernible ridge rather than bluntly triangular.

Description of holotype male. Head (Fig. 4c). Labium pale. Mandible bases pale and brown. Labrum pale, extensive brown marks in basal half. Genae brownish grey, this colour extended along eye margins to level of antenna. Anteclypeus brownish. Postclypeus black. Frons black, angulate, antefrons with pale transverse stripe, interrupted centrally. Rest of dorsum of head dark bronzy, with pale streak on the anterior margin of scape, pale brownish pedicel, faint brownish ovoid streak between antennae and lateral ocelli and brownish hind margin of the occiput; underside of head extensively pale.

Thorax. Prothorax (Fig. 9c) brownish except black anterior carina of anterior pronotal lobe, extended onto central part of rest, dorsal part of middle pronotal lobe; posterior pronotal lobe simple, dark basally and centrally. Synthorax (Fig. 14b) entirely pale orange brown except for dark metallic green inner half of mesepisternum, narrowly connected to black elongate streak at near wing bases along mesopleural suture, some small black intrusions from antealar carina and small brown mark near wing bases on metapleural suture. Legs almost entirely pale except some dark marks at distal extremities of femurs, spines, and brown tarsi with black tip without denticle. Wings hyaline with black veins; Arculus opposite Ax2; Ac near Ax2; petiolation ceases at the level of arculus; R4 before subnodus; IR3 at subnodus; 15 (right) or 14 (left) $\mathrm{Px}$ in $\mathrm{Fw}, 13$ in $\mathrm{Hw}$. Pterostigma trapezoidal, brown with prominent pale margin, costal side half the length of subcostal side, covering ca one underlying cell.

Abdomen. S1-3 brown dorsally, pale lower laterally. S4-7 brown, becoming darker distally, faint incomplete basal annulus present; S8-S10 dark brown, with some indistinct paler markings lower laterally. Cerci (Figs 18c, 18d) dark brown, ca twice as long as S10. In lateral view upper branch directed gently up in its basal half then gently down, sub-cylindrical basally, slightly expanded after ca midpoint before narrowing apically to tip. In dorsal view gently curved, forceps like, hooked in at apex where it bears a ventral incurved sharp tooth.
Lower branch slender, sub cylindrical, gently tapering from base to in turned black tip.

Genital ligula. Shaft lacking a prominent tubercle, possessing merely a low ridge at this position (Fig. 1b).

Measurements (mm). Abdomen including anal appendages 54, Hw 33.

Description of female from Leyte (based on that from Sta. Cruz, $14 \times$ 1915). Similar to male except as noted.

Thorax. Prothorax (Figs 9d, 10f) orange-brown, black on anterior carina of anterior pronotal lobe not extended onto rest of lobe, dorsal part of middle pronotal lobe only black centrally (Fig. 10f), posterior pronotal lobe with black transverse basal band centrally. Posterior pronotal lobe sub rectangular in dorsal view (Fig. 10f), a pair of shallow apical depressions on either side of the center, almost square in lateral view (Fig. 9d), free corners rounded. Synthorax (Figs 14d, 14f) lacking dark markings laterally. Wings with 15 (left) or 18 (right) Px in Fw, 16 (left) or 15 (right) Px in Hw. Pterostigma in left Hw almost square but wing margin distorted in this area.

Abdomen. S9 mostly black, S10 entirely black (Fig. 15f). Cerci black, pointed, ovipositor (styles missing) black and brown, only just extending beyond posterior margin of S10.

Measurements (mm). Abdomen including ovipositor 52, Hw 33.

Distribution: Samar. ?Leyte and ?Mindanao islands

Remarks. The Samar and Leyte populations are provisionally assigned to this species pending availability of more material. Unfortunately no female from Mindanao is present in the RMNH collection, so that a female from Leyte had to be used for illustration.

Pericnemis incallida-group spec. indet. A

Amphicnemis sp. n.;- Villanueva 2010: 7, Fig. 2c (Polillo).

Material examined. $1 \mathrm{fH}$, Tamulaya, Polillo, Polillo Island, Quezon province, 30 iii 2010, leg. RJTV \& H. Cahilog, in coll. RJTV.

Remarks. The posterior pronotal lobe of this specimen is quite distinct. However, in the absence of the male at the moment we have decided to leave the taxonomic status of this population open. 
Pericnemis incallida-group spec. indet. B

Amphicnemis spec. nov.; - Villanueva 2009: 8, 9 (Calayan).

Material examined. $2 \mathrm{fH} \mathrm{f}$, Lungog, Macsidel, Calayan Municipality, Calayan Island, Cagayan province, 25 iv 2008, leg. RJTV, in coll. RJTV.

Remarks. The identity of these female specimens remains open until male specimens become available.

\section{Pericnemis incallida-group spec. indet. C}

Material examined. $1 \mathrm{f}$, Apayao, Flora, Santa Maria, Barangay Binugauan, Luzon, 14-20 iv 1997, leg. C.M. Nazareno, in RMNH; 1 f\#, Baggao, San Miguel, Napalo, Pared River, Cagayan, Luzon, 1997, leg. A. Buenafe \& A. Goro, in RMNH.

Remarks. These female specimens closely resemble P.incallida. We refrain from commenting on the taxonomic status of this population pending the availability of male specimens.

\section{Acknowledgements}

The authors are indebted to KD Dijkstra, Matti Hämäläinen, Vincent Kalkman and Jan van Tol for their constant support to this odonatological study, for the various help during the preparation of this manuscript, and for the discussion and company while in Leiden. Special thanks to Dirk Gassmann for the discussion, company and various help and advices during the first author's stay in Leiden. Rosser Garrison provided some literature and relevant information. The authors are also thankful to the late Victor Gapud for permission to study his collection and Chung-Ping Lin for the joint excursion resulting to the discovery of several new species. Pericnemis bisaya was collected during fieldwork supported with a grant received from the Chicago Board of Trade Endangered Species Fund. This paper is one of the results of the first author's visit to the RMNH-Naturalis sponsored by the Martin Fellowship.

\section{Literature Cited}

Choong, C.Y., Y.F. Ng \& R.A. Dow, 2012. Odonata from three forests of central Terengganu, Malaysia. Malayan Nature Journal, 64(2), 95-104.

Gapud, V.P., 2006. Damselflies (Odonata: Zygoptera) of Greater Luzon, Philippines with description of two new species. Philippine Entomologist, 19(2), 1-42.
Hämäläinen, M. \& R.A. Müller, 1997. Synopsis of the Philippine Odonata, with lists of species recorded from forty islands. Odonatologica, 26(3), 249-315.

Lieftinck, M.A., 1957. On some old types of Coenagrionine Odonata described from the Philippine Islands, with notes on allied species. Zoologische Mededelingen, 35(13), 161175.

Needham, J.G., \& M.K. Gyger, 1939. The Odonata of the Philippines, II. Suborder Zygoptera. The Philippine Journal of Science, 70 (3), 239-314, plates 11-22.

Needham, J.G., \& M.K. Gyger, 1941. More Odonata from the Philippines. The Philippine Journal of Science, 74(2), 141151, plate I.

Orr, A. G. \& M. Hämäläinen, 2013. Two new species of Pericnemis from Borneo, with comparative notes on related species (Zygoptera: Coenagrionidae). Odonatologica, 42(4), 335-345.

Ramos, L.G. \& V.P. Gapud, 2007. Survey of dragonflies and damselflies (Odonata) of Mount Makiling, Luzon, Philippines. Philippine Entomologist, 21(1), 1-75.

Villanueva, R.J.T., 2009. Dragonflies of Babuyan and Batanes group of islands, Philippines (Insecta: Odonata). International Dragonfly Fund - Report, 17, 1-16.

Villanueva, R.J.T., 2010. Odonata fauna of Polillo Island revisited. International Dragonfly Fund - Report, 27, 1-16.

Villanueva, R.J.T., 2012. Review of the Philippine taxa formerly assigned to the genus Amphicnemis Selys. Part I: Overview and descriptions of three new genera (Odonata: Coenagrionidae). Zoologische Mededelingen, 86(8), 579604.

Villanueva, R.J.T. \& R.A. Dow, 2014. Review of the Philippine taxa formerly assigned to the genus Amphicnemis Selys, II. Genus Sangabasis with descriptions of eight new species (Odonata: Coenagrionidae). Zootaxa, 3815(1), 1-28. 